\title{
Evaluating simulated primary anthropogenic and biomass burning organic aerosols during MILAGRO: implications for assessing treatments of secondary organic aerosols
}

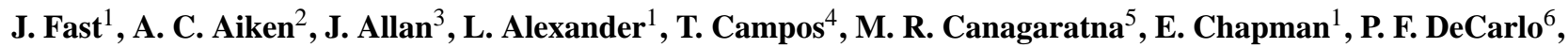 \\ B. de Foy ${ }^{7}$, J. Gaffney ${ }^{8}$, J. de Gouw ${ }^{9}$, J. C. Doran ${ }^{1}$, L. Emmons ${ }^{4}$, A. Hodzic ${ }^{4}$, S. C. Herndon ${ }^{5}$, G. Huey ${ }^{10}$, J. T. Jayne ${ }^{5}$, \\ J. L. Jimenez ${ }^{2}$, L. Kleinman ${ }^{11}$, W. Kuster ${ }^{9}$, N. Marley ${ }^{8}$, L. Russell ${ }^{12}$, C. Ochoa ${ }^{13}$, T. B. Onasch ${ }^{5}$, M. Pekour ${ }^{1}$, C. Song ${ }^{1}$, \\ I. M. Ulbrich ${ }^{2}$, C. Warneke ${ }^{9}$, D. Welsh-Bon ${ }^{9}$, C. Wiedinmyer ${ }^{4}$, D. R. Worsnop ${ }^{5}$, X.-Y. Yu ${ }^{1}$, and R. Zaveri ${ }^{1}$ \\ ${ }^{1}$ Pacific Northwest National Laboratory, Richland, Washington, USA \\ ${ }^{2}$ University of Colorado, Boulder, Colorado, USA \\ ${ }^{3}$ University of Manchester, Manchester, UK \\ ${ }^{4}$ National Center for Atmospheric Research, Boulder, Colorado, USA \\ ${ }^{5}$ Aerodyne Research Inc., Billerica, Massachusetts, USA \\ ${ }^{6}$ Paul Scherrer Institut, Switzerland \\ ${ }^{7}$ Saint Louis University, Saint Louis, Missouri, USA \\ ${ }^{8}$ University of Arkansas - Little Rock, Little Rock, Arkansas, USA \\ ${ }^{9}$ NOAA Earth System Research Laboratory \& Cooperative Institute for \\ Research in Environmental Sciences, University of Colorado, Boulder, Colorado, USA \\ ${ }^{10}$ Georgia Institute of Technology, Atlanta, Georgia, USA \\ ${ }^{11}$ Brookhaven National Laboratory, Upton, New York, USA \\ ${ }^{12}$ University of California, San Diego, San Diego, California \\ ${ }^{13}$ Universidad Nacional Autónoma de México, Mexico City, Mexico
}

Received: 10 January 2009 - Published in Atmos. Chem. Phys. Discuss.: 24 February 2009

Revised: 17 July 2009 - Accepted: 15 August 2009 - Published: 31 August 2009

\begin{abstract}
Simulated primary organic aerosols (POA), as well as other particulates and trace gases, in the vicinity of Mexico City are evaluated using measurements collected during the 2006 Megacity Initiative: Local and Global Research Observations (MILAGRO) field campaigns. Since the emission inventories, transport, and turbulent mixing will directly affect predictions of total organic matter and consequently total particulate matter, our objective is to assess the uncertainties in predicted POA before testing and evaluating the performance of secondary organic aerosol (SOA) treatments. Carbon monoxide (CO) is well simulated on most days both over the city and downwind, indicating that transport and mixing processes were usually consistent with the meteorological conditions observed during MILAGRO. Pre-
\end{abstract}

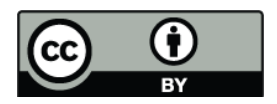

Correspondence to: J. D. Fast (jerome.fast@pnl.gov) dicted and observed elemental carbon (EC) in the city was similar, but larger errors occurred at remote locations since the overall $\mathrm{CO} / \mathrm{EC}$ emission ratios in the national emission inventory were lower than in the metropolitan emission inventory. Components of organic aerosols derived from Positive Matrix Factorization of data from several Aerodyne Aerosol Mass Spectrometer instruments deployed both at ground sites and on research aircraft are used to evaluate the model. Modeled POA was consistently lower than the measured organic matter at the ground sites, which is consistent with the expectation that SOA should be a large fraction of the total organic matter mass. A much better agreement was found when modeled POA was compared with the sum of "primary anthropogenic" and "biomass burning" components derived from Positive Matrix Factorization (PMF) on most days, especially at the surface sites, suggesting that the overall magnitude of primary organic particulates released was reasonable. However, simulated POA

Published by Copernicus Publications on behalf of the European Geosciences Union. 
from anthropogenic sources was often lower than "primary anthropogenic" components derived from PMF, consistent with two recent reports that these emissions are underestimated. The modeled POA was greater than the total observed organic matter when the aircraft flew directly downwind of large fires, suggesting that biomass burning emission estimates from some large fires may be too high.

\section{Introduction}

Most predictions of organic matter made by threedimensional particulate models are currently significantly too low because the processes contributing to secondary organic aerosol (SOA) formation and transformation are not well understood. One objective of the Megacity Initiative: Local and Global Research Observations (MILAGRO) field campaign (Molina et al., 2008) conducted during March 2006 was to obtain measurements of organic aerosols and precursors of secondary organic aerosols (SOA). Measurements during MILAGRO (e.g. Kleinman et al., 2008; de Gouw et al., 2009) and other field campaigns worldwide (de Gouw et al., 2005; Simpson et al., 2007; Hodzic et al., 2006; Zhang et al., 2007) have indicated that, as a result of secondary organic aerosol (SOA) formation processes, organic aerosol mass is much higher than one would expect from primary emissions and dispersion. However, the understanding of how anthropogenic and biogenic precursors contribute to SOA formation is far from complete. It is therefore not surprising that simulated organic aerosol mass from recent modeling studies have been shown to be a factor of five or more lower than observed (e.g. Volkamer et al., 2006).

Many 3-D chemical transport models employ SOA formulations based on Koo et al. (2003) and Odum et al. (1996). Additional SOA precursors that were previously ignored have been proposed (e.g. Robinson et al., 2007) that can produce significantly more SOA mass (Dzepina et al., 2009) than traditional approaches, but the newer approaches have their own set of assumptions that await additional testing and evaluation. Improving predictions of organic aerosols is important in terms of both air quality and climate applications. For climate applications, the current under-prediction of organic aerosol mass will subsequently affect predictions of direct radiative forcing by affecting scattering and absorption of radiation in the atmosphere. Predictions of indirect radiative forcing will be affected as well because the size distribution and chemical composition will affect aerosol hygroscopic properties, activation of cloud condensation nuclei, ice nuclei, and cloud chemistry.

The goal of this study is to determine whether regional 3 -D models operated in a reasonable configuration can adequately predict concentrations of primary organic aerosols (POA). Accurate predictions of POA are needed since it contributes to the total particulate mass and influences the inter- pretation of total organic matter (OM). Factor analysis methods, such as Positive Matrix Factorization (PMF), combined with mass spectra from the Aerodyne Aerosol Mass Spectrometer (AMS) have recently been applied to derive components of organic aerosols including: hydrocarbon-like organic aerosol (HOA), oxidized organic aerosol (OOA), and biomass burning organic aerosols (BBOA) (e.g. Zhang et al., 2005, 2007; Lanz et al., 2007; Ulbrich et al., 2009). The temporal variation of HOA has been shown to be similar to that of primary emissions of other species in urban areas, whereas OOA is better correlated with species that are formed as a result of photochemical activity (Kondo et al., 2007; Docherty et al., 2008; Herndon et al., 2008). PMF of high-resolution AMS spectra (DeCarlo et al., 2006) results in better separation of the components due to the larger differences in the spectra, especially between HOA and BBOA which have more similar unit-resolution spectra but very different high-resolution spectra (Aiken et al., 2009a; Ulbrich et al., 2009). The BBOA retrieved from PMF is assumed to be composed mainly of primary biomass burning aerosols; the spectra of secondary organic aerosols from biomass burning precursors are more similar to OOA (Grieshop, 2009).

In this study, the WRF-chem model is used with trace gas and particulate release rates derived from gridded versions of the 1999 National Emissions Inventory and the 2002 Mexico City Metropolitan Area (MCMA) as adjusted by Lei et al. (2007) to predict POA and other tracers in the vicinity of Mexico City during the 2006 Megacity Initiative: Local and Global Research Observations (MILAGRO) field campaigns. Uncertainties in both the primary emission estimates and the simulated meteorological processes will affect predictions of total organic matter and consequently total particulate matter; therefore, our objective is to assess the uncertainties in predicted POA before testing and evaluating the performance of SOA treatments. In contrast to many large cities, Mexico City is a challenging location to evaluate particulate models because of the multiple anthropogenic, biomass burning, volcanic, and dust sources of primary particulates and particulate precursors. SOA in the vicinity of Mexico City originating from biogenic precursors are expected to be low in concentration during the dry season, although biogenic SOA formed from emissions on the coastal ranges may make a contribution to background organic aerosols over Central Mexico (Hodzic et al., 2009). A wide range of continuous surface measurements and intermittent aircraft measurements is used to evaluate the model. Organic aerosol predictions are evaluated using data from AMS instruments (e.g. Canagaratna et al., 2007) deployed at four ground sites and onboard two research aircraft. Estimates of POA from PMF analysis are currently available for three of the ground sites and for some aircraft flights.

We first briefly discuss the performance of simulated meteorology and carbon monoxide (CO) to show that transport and mixing is reasonably represented on most days during the simulation period over Mexico and that $\mathrm{CO}$ emission 
Table 1. Selected WRF-Chem configuration options for this study.

\begin{tabular}{ll}
\hline Atmospheric Process & WRF-Chem Option \\
\hline Advection & Positive Definite \\
Longwave radiation & RRTM \\
Shortwave radiation & Goddard \\
Surface layer & MM5 similarity theory \\
Land surface & Noah \\
Boundary layer & YSU \\
Cumulus clouds & Kain-Fritsch (outer domain only) \\
Cloud microphysics & Enhanced Purdue Lin \\
Gas phase chemistry & CBM-Z \\
Aerosol chemistry & MOSAIC \\
Aqueous chemistry & Fahey and Pandis \\
Photolysis & Fast-J \\
\hline
\end{tabular}

estimates are adequate. Then, predictions of black carbon and organic matter are evaluated with the available measurements made during MILAGRO. Modeled POA was consistently lower than the measured organic matter at the ground sites, which is consistent with the expectation that SOA is typically a large fraction of the total organic aerosol mass. A much better agreement was found when modeled POA was compared with the sum of measured HOA and BBOA, suggesting that the emission rates were reasonable overall. A similar conclusion was obtained using the AMS instruments on the aircraft on days with relatively low biomass burning. On days with a significant number of fires, the predicted POA was greater than the total observed organic matter as the aircraft flew directly downwind of the biomass burning sources. One or more factors may contribute to this error including biomass burning emissions that were too high, the validity of assumptions employed to derived biomass burning estimates from satellite remote sensing, and errors in way the model treated plume rise or horizontal mixing of point sources.

\section{Model description}

Version 3 of the Weather Research and Forecasting (WRF) community model that simulates trace gases and particulates simultaneously with meteorological fields (Grell et al., 2005) is used in this study. The chemistry version of WRF, known as WRF-Chem, contains several treatments for photochemistry and aerosols developed by the user community.

Table 1 lists the specific treatments employed for meteorology, trace gas, and particulate processes used in this study that are described elsewhere (Skamarock et al., 2008). Atmospheric chemistry is simulated using the CBM-Z photochemical mechanism (Zaveri and Peters, 1999), the FastJ photolysis scheme (Wild et al., 2000), and the MOSAIC aerosol model (Zaveri, et al., 2008). MOSAIC employs the sectional approach for the aerosol size distribution in which both mass and number are predicted for each size bin. Eight size bins are used ranging from 0.039 (lower bound) to $10 \mu \mathrm{m}$ (upper bound). An internal mixture assumption is used so that all particles within a bin have the same chemical composition. There are no separate hydrophilic and hydrophobic species of organic matter and elemental carbon. The hygroscopic properties for all particles within a size bin are computed assuming internal mixing as the volumeweighted bulk hygroscopicity for each chemical composition. MOSAIC includes treatments for nucleation (Wexler et al., 1994), coagulation (Jacobson et al., 1994), and dry deposition (Binkowski and Shankar, 1995). Aerosols influence the scattering and absorption of solar radiation (i.e. the aerosol direct effect) and photolysis rates through the use of extinction, single-scattering albedo, and asymmetry factor parameters. These parameters are computed as a function of wavelength using refractive indices based on predicted particulate mass, composition, and wet radius for each size bin (Fast et al., 2006). Treatments for aqueous chemistry, cloudaerosol interactions, aerosol indirect effects, and wet deposition (Gustafson et al., 2007; Chapman et al., 2008) are also included; however, these processes were not significant prior to the cold surge on 23 March (Fast et al., 2007) since mostly sunny conditions were observed and simulated over the central Mexican plateau.

It is important to note that MOSAIC does not include a treatment of SOA for version 3 of WRF-Chem and that all organic matter is treated as non-volatile POA. A more recent 0 -D version of MOSAIC now incorporates gas-to-particle partitioning processes for SOA similar to the approach used by the MADE/SORGAM aerosol model (Ackermann et al., 1998; Schell et al., 2001); nevertheless, a test simulation using MADE/SORGAM in WRF-Chem produced SOA concentrations less than $1 \mu \mathrm{g} \mathrm{m}^{-3}$ that were considerably lower than observed SOA during MILAGRO (e.g. Herndon et al., 2008; Kleinman et al., 2008; Aiken et al., 2009). Understanding the specific gas-to-particle partitioning processes responsible for SOA formation and translating those findings into treatments suitable for models is the subject of on-going research.

Therefore, the purpose of this study is to evaluate predictions of POA so that SOA treatments can be evaluated later (e.g. Hodzic et al., 2009) using the current assessment of the uncertainties in dispersion and the emission inventories. If one assumes POA is non-volatile, then errors in POA predictions will results from uncertainties in the emission inventories, transport and mixing processes, and deposition. Some studies (including those for Mexico City) have recently shown that POA is semi-volatile (Robinson et al., 2007; Huffman et al., 2008, 2009a, b), but this issue and its implementation into models have not been fully resolved. The implications of assuming non-volatile POA are described later. 
Table 2. List of MILAGRO instrumentation and measurements employed in this study. All particulate concentrations in this paper are for ambient conditions, rather than at standard temperature and pressure (STP).

\begin{tabular}{lll}
\hline Instrument or Platform & Location(s) & Measurements \\
\hline RAMA air quality monitoring network & Mexico City & winds, CO, PM $2.5, \mathrm{PM}_{10}$ \\
Radar wind profiler & T1 and Veracruz & winds. PBL depth \\
Radiosondes & $\mathrm{T} 1$ & PBL depth \\
Micropulse Lidar & $\mathrm{T} 1$ & PBL depth \\
Thermo Environmental Systems, Model 48C & $\mathrm{T} 1$ & $\mathrm{CO}$ \\
Tapered Element Oscillating Microbalance (TEOM) & $\mathrm{T} 1$ & $\mathrm{PM}_{2.5}$ mass \\
Aethelometer & T0 & black carbon \\
Particle Soot Aerosol Photometer \& & Paso de Cortes & black carbon \\
Photoacoustic Aerosol Spectrometer & & \\
Sunset Laboratory OC/EC Carbon Aerosol Analyzer & T1, T2 & organic and black carbon (PM 2.5$)$ \\
Aerodyne Aerosol Mass Spectrometer (AMS) & T0*, T1, Paso de Cortes, & organic matter (PM $)$ \\
& Pico Tres Padres & \\
Gas chromatograph with flame-ionization (GC-FID) & T1 & alkanes, alkenes, acetylene \\
Proton-transfer Ion Trap Mass Spectrometry (PIT-MS) & T1 & aromatics, oxygenated VOCs \\
G-1 aircraft & variable & winds, CO, organic matter \\
C-130 aircraft & variable & winds, CO, organic matter \\
DC-8 aircraft & variable & winds, CO \\
\hline
\end{tabular}

* AMS instruments deployed at T0 and on the C-130 were high-resolution versions (DeCarlo et al., 2006), while the rest were unit resolution versions (Canagaratna et al., 2007)

\section{Experimental method}

\subsection{MILAGRO measurements}

MILAGRO was composed of five collaborative field experiments conducted during March 2006 (Molina et al., 2008). The MCMA-2006 field experiment, supported by various Mexican institutions and the US National Science Foundation (NSF) and Department of Energy (DOE), obtained measurements at several surface sites over the city. Measurements over the city and up to a hundred kilometers downwind of the city were obtained from six research aircraft associated with the Megacities Aerosol Experiment (MAX-Mex) supported by the DOE, the Megacities Impact on Regional and Global Environments - Mexico (MIRAGE-Mex) field experiment, supported by the NSF and Mexican agencies, the Intercontinental Transport Experiment B (INTEX-B), supported by the National Aeronautical and Space Administration (NASA), and a biomass burning effort supported by the USDA Forest Service and the NSF. MILAGRO is the largest of a series of international campaigns in and around Mexico City, which also includes IMADA-AVER in 1997 (Edgerton et al., 1999) and MCMA-2003 (Molina et al., 2007).

One objective of MILAGRO was to collect measurements over a wide range of spatial scales to describe the evolution of the Mexico City pollutant plume from its source and up to several hundred kilometers downwind. The flight paths for three of the research aircraft are shown in Fig. 1a and b. The G-1 aircraft flew primarily over and northeast of the city to obtain information on the local processing of pollutants
(Kleinman et al., 2008). Regional-scale measurements over Mexico City, the central Mexican plateau, and the Gulf of Mexico were obtained from the C-130 aircraft (e.g. DeCarlo et al., 2008; Shon et al., 2008). The DC-8 aircraft obtained measurements over the largest spatial scales between Mexico City and Houston (Molina et al., 2008). Extensive surface chemistry and meteorological profiling measurements were made at three "supersites" denoted by T0, T1, and T2 in Fig. 1c (e.g. Doran et al., 2007; Shaw et al., 2007). A more limited set of measurements was obtained at several other sites in the vicinity of Mexico City.

The specific measurements used in this study, listed in Table 2, are discussed later in more detail when compared against model predictions.

\subsection{Model configuration}

A simulation period between 06:00 UTC (midnight local standard time) 6 March and 06:00 UTC 30 March was chosen that included most of the airborne and surface measurements that were operational during MILAGRO. Two computational domains were employed. The outer domain (Fig. 1a) encompasses Mexico east of Baja California, southern Texas, and a portion of Central America using a 12-km grid spacing. The extent of the inner domain (Fig. 1b), encompassing central Mexico and a large portion of the Gulf of Mexico using a $3-\mathrm{km}$ grid spacing, was chosen to include a large fraction of the aircraft flight paths.

The initial and boundary conditions at 6-h intervals for the meteorological variables were obtained from the National 


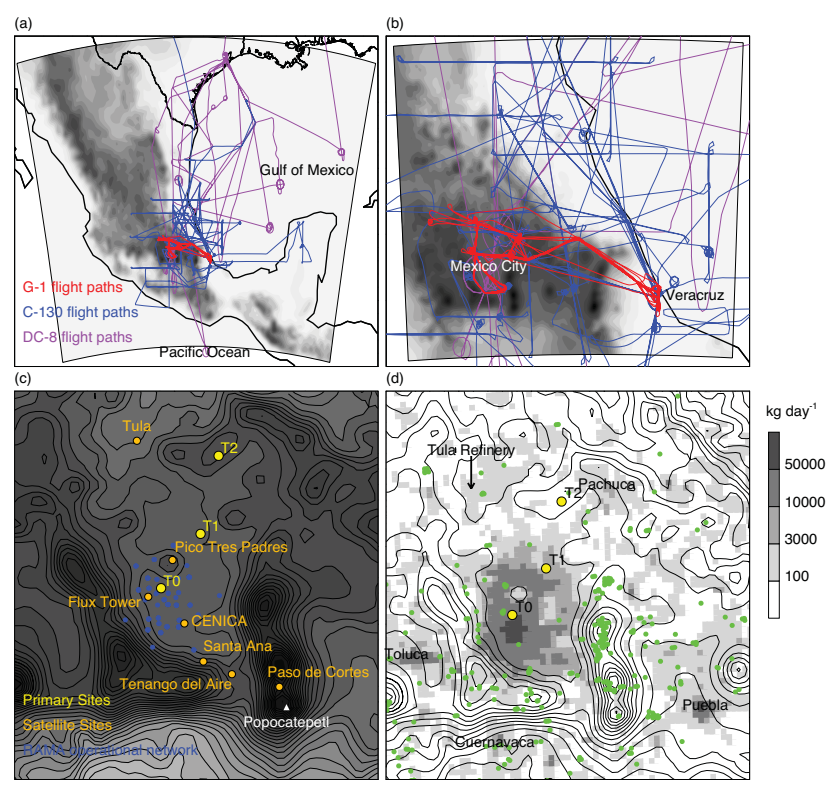

Fig. 1. WRF-chem modeling domains that depict topographic variations over the (a) outer domain $(\Delta \mathrm{x}=12 \mathrm{~km})$ encompassing Mexico and (b) inner domain $(\Delta \mathrm{x}=3 \mathrm{~km})$ encompassing the central Mexican plateau and portions of the Gulf of Mexico. Lines denote local, regional, and synoptic-scale flight paths made by the G-1, C-130 and DC- 8 aircraft. The locations of the three supersites, other research sites, and operational monitoring network in the vicinity of Mexico City are shown in (c). Emissions of CO over central Mexico based on the 1999 National Emissions Inventory and the 2002 MCMA emissions inventory is shown in (d), where green dots denote the locations of biomass burning sources during March 2006 obtained from MODIS thermal anomaly satellite data.

Center for Environmental Prediction's Global Forecast System (GFS) model. Initial ocean temperatures, soil temperatures, and soil moisture were also obtained from the GFS model. In addition to constraining the boundary conditions to the large-scale analyzed meteorology, four-dimensional data assimilation was used to nudge (Liu et al., 2006; Doran et al., 2008) the predicted wind, temperature, and specific humidity to the observations obtained from the radar wind profilers and the radiosondes at the T0, T1, T2 sites (Fig. 1c) and the operational radiosondes in Mexico.

The initial and boundary conditions at 6-h intervals for $\mathrm{CBM}-\mathrm{Z}$ and MOSAIC variables were obtained from 34 trace gases and 12 particulate species produced by the MOZART4 global chemistry model (Pfister et al., 2008) run with a grid spacing of $2.8 \times 2.8$ degrees. Boundary condition values for long-lived species, such as $\mathrm{CO}$ and ozone, have an impact on WRF-Chem predictions over central Mexico. The concentrations of most other species are produced primarily by emissions within the modeling domain rather than by long-range transport. For example, ambient background particulate concentrations in the lower to middle troposphere over the Pacific Ocean were typically between 1 and $5 \mu \mathrm{g} \mathrm{m}^{-3}$. Most of this mass was composed primarily of $\mathrm{SO}_{4}, \mathrm{NO}_{3}, \mathrm{NH}_{4}$, and dust. Elemental carbon (EC) and organic matter (OM) was usually much less than 0.1 and $0.5 \mu \mathrm{g} \mathrm{m}^{-3}$, respectively, and consequently contributed little to the overall concentration of carbonaceous particulates over central Mexico.

\subsection{Emission inventories}

Emissions of trace gases and particulates were obtained from two inventories: the 2002 Mexico City Metropolitan Area (MCMA) inventory as adjusted by Lei et al. (2007) and the 1999 National Emissions Inventory (NEI).

The original 2002 MCMA inventory was developed by the Comisión Ambiental Metropolitana (CAM, 2004). Lei et al. (2007) describe how the annual emissions were mapped into grid cells with a resolution of $2.25 \mathrm{~km}$ encompassing the Mexico City Valley. Previous studies have suggested that volatile organic compounds (VOC) emission estimates were too low when compared with measurements made during recent field campaigns (e.g. Molina and Molina, 2002). Consequently, Lei et al. (2007) increased the total mass of VOC released by $65 \%$, although their adjustment factors varied among the specific hydrocarbon species. The resulting Lei et al. (2007) gridded inventory contains diurnally-varying mobile, area, and point source emission rates for 26 trace-gas and 13 particulate species representative of a typical weekday. As in Lei et al. (2007), typical weekday emissions from mobile sources in our investigation were reduced by $10 \%$ on Saturdays and $30 \%$ on Sundays and holidays to capture weekdays/weekend variations. The $\mathrm{PM}_{2.5}$ emissions were composed of four components: primary organic matter, elemental carbon, other inorganic material, and crustal material. The ratio of the mass emitted by each component to the total $\mathrm{PM}_{2.5}$ mass varied over the Mexico City basin. Total $\mathrm{PM}_{2.5}$ and $\mathrm{PM}_{10}$ emissions in this study were not adjusted from the original inventory.

The 1999 NEI inventory was developed by Mexico's Secretariat of the Environment and National Resources, the US Environmental Protection Agency, and several other groups (http://www.epa.gov/ttn/chief/net/mexico.html). Annual emission estimates of $\mathrm{CO}, \mathrm{NO}_{\mathrm{x}}, \mathrm{SO}_{2}$, total VOCs, $\mathrm{NH}_{3}$, $\mathrm{PM}_{2.5}$, and $\mathrm{PM}_{10}$ were developed for point, area, and mobile sources. This inventory was converted to a $\sim 2.5 \mathrm{~km}$ grid that is more useful to modelers by using population and road proxies. Emissions of $\mathrm{CO}, \mathrm{NO}_{\mathrm{x}}, \mathrm{SO}_{2}, \mathrm{VOC}, \mathrm{NH}_{3}, \mathrm{PM}_{2.5}$, and $\mathrm{PM}_{10}$ are available for point, area, and mobile sources. Due to the absence of speciation recommendations from inventory developers, total VOCs were divided by mass into 13 hydrocarbons using a mean speciation profile derived by averaging over all the grid cells in the Lei et al. (2007) modified 2002 MCMA inventory. Similarly, 1999 NEI inventory estimates of fine and coarse particulate matter was divided into primary organic, black carbon, and inorganic species by computing an average ratio of these species to the total $\mathrm{PM}_{2.5}$ emitted over all the grid cells in the 2002 MCMA inventory. 
Table 3. Annual particulate and trace gas emission rates (tons/year) over the MCMA and at the Tula industrial complex, located $\sim 45 \mathrm{~km}$ north of the MCMA. Also included are the emission estimates from biomass burning and volcanic sources for March 2006.

\begin{tabular}{|c|c|c|c|c|c|c|c|}
\hline Inventory & $\mathrm{PM}_{10}$ & $\mathrm{PM}_{2.5}$ & $\mathrm{SO}_{2}$ & $\mathrm{CO}$ & $\mathrm{NO}_{\mathrm{x}}$ & VOC & $\mathrm{NH}_{3}$ \\
\hline $2000 \mathrm{M}$ & 10341 & 6033 & 10004 & 2035,425 & 193451 & 429755 & 15446 \\
\hline $2002 \mathrm{MCMA}^{1}$ & 23542 & 6777 & 8585 & 1941593 & 188262 & 490100 & 16933 \\
\hline 2004 MCMA & 20686 & 6662 & 6646 & 1792,081 & 179996 & 532168 & 17514 \\
\hline 2006 & 22951 & 6089 & 6913 & 1990336 & 191262 & 576616 & 19936 \\
\hline $1999 \mathrm{NEI}^{2}$ & 31890 & 25159 & 38195 & 1592665 & 177599 & 477137 & 47651 \\
\hline Tula $^{3}$ & 17227 & 12307 & 382917 & 5768 & 203481 & 2293 & 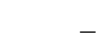 \\
\hline Biomas & 12670 & 11635 & 770 & 86588 & 6178 & 5945 & 890 \\
\hline Volcanic $^{5}$ & - & - & 52598 & - & - & - & . \\
\hline
\end{tabular}

${ }^{1}$ Estimates from the original MCMA emissions inventory; VOC emissions were increased by 65\% in this study as in Lei et al. (2007).

2 Only for area encompassing the MCMA inventory

3 Includes multiple stack information

${ }^{4}$ Encompassing the MCMA and surrounding valleys between $100-98^{\circ} \mathrm{W}$ and $18.5-20.5^{\circ} \mathrm{N}$ fo March 2006

5 Only from Popocatepetl, located $\sim 60 \mathrm{~km}$ southeast of Mexico City, for March 2006

This ratio is adjusted slightly to include a small amount of $\mathrm{SO}_{4}(2 \%)$ and $\mathrm{NO}_{3}(0.2 \%)$ emissions based on typical urban emissions in the US While $\mathrm{PM}_{2.5}$ emission rates vary over Mexico, the relative amount of organic, black carbon, inorganic, $\mathrm{SO}_{4}$, and $\mathrm{NO}_{3}$ is constant. Since the inventory contains annual estimates for each grid cell, we assumed that the hourly and weekend/weekday variations were the same as employed for the 2002 MCMA inventory and Lei et al. (2007).

Gridded versions of the 2006 MCMA inventory were not yet available at the time of this study, but the annual emissions estimates for the 2002 and 2006 inventories were similar as indicated in Table 3. Also listed in Table 3 are values for the subset of the 1999 NEI inventory obtained by summing over the same area covered by the MCMA inventory. The NEI values over Mexico City are all significantly different than those reported by the local inventory for 2000, especially for $\mathrm{PM}, \mathrm{SO}_{2}$ and $\mathrm{NH}_{3}$. In this study, 2002 MCMA emissions with VOCs adjusted as in Lei et al. (2007) are used in the Mexico Valley and the 1999 NEI emissions are used elsewhere. Figure 1d shows the resulting yearly emission of particulate matter in the vicinity of Mexico City for the 3-km grid in relation to the MILAGRO primary surface sampling sites. T0 is located close to the highest emission rates in the city while $\mathrm{T} 1$ is located at the edge of the city. The emission rates in the immediate vicinity of the remote $\mathrm{T} 2$ site are low.

In addition to anthropogenic sources within Mexico City, there are also other large emission sources over central Mexico. While most of the point sources within the Mexico City valley are relatively small, the Tula industrial complex located $\sim 45 \mathrm{~km}$ north of the MCMA (Fig. 1d) emits large amounts of $\mathrm{NO}_{\mathrm{x}}, \mathrm{SO}_{2}$, and PM, according to the 1999 NEI emission inventory (Table 3). $\mathrm{NO}_{\mathrm{x}}$ and $\mathrm{PM}$ annual emissions are about the same order of magnitude as in Mexico City, while $\mathrm{SO}_{2}$ is $\sim 50$ times higher than Mexico City. Emissions of $\mathrm{CO}$ and VOCs are much lower than Mexico City. When the winds are from the north, emissions from Tula can be transported over Mexico City (e.g. de Foy et al., 2007). When the winds are southerly to southwesterly, it is possible that the Mexico City and Tula pollutant plumes merge as they are transported northeastward.

Biomass burning is also a significant source of trace gas and particulates over Mexico (Yokelson et al., 2007; Molina et al., 2007; DeCarlo et al., 2008; Aiken et al., 2009). Daily estimates of trace gas and particulate emissions from fires were obtained using the MODIS thermal anomalies product on the Terra and Aqua satellites and land cover information as described by Wiedinmyer et al. (2006). A diurnal variation in the emission rates, with a peak value at 20:00 UTC (14:00 LT) and a minimum value at sunrise, was applied to distribute the daily estimates over time. The emissions were distributed uniformly within $\sim 300 \mathrm{~m}$ of the ground, because insufficient information was available to perform plume rise calculations. The MODIS thermal anomaly methodology can underestimate the number of fires for two reasons: clouds that obscure fires from the measurements and twice-daily overpass times that do not provide enough temporal information on short-lived fires. For example, many fires sampled by aircraft were small shrub and agricultural clearing fires that were not detected by satellite (Yokelson et al., 2007). The MODIS thermal anomaly methodology may also assume most of a pixel area is burning even when a fire occupies a small portion of the pixel. Flaming versus smoldering combustion that varies during the coarse of a fire is not taken into account as well. While biomass burning estimates derived from MODIS are the most readily available information for models, their uncertainties must be taken into account when assessing smoke plumes predicted by models. 

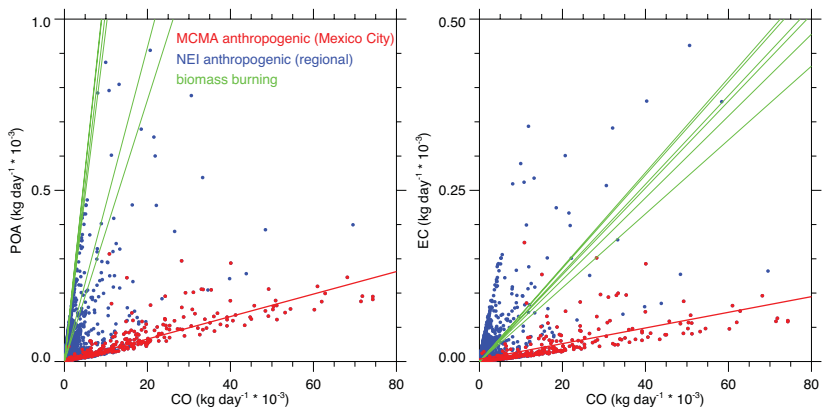

Fig. 2. Scatter plots of POA and EC emissions versus those for $\mathrm{CO}$ over the central Mexican plateau where red and blue dots denote grid cells that employ the 2002 MCMA inventory and 1999 National Emissions Inventory, respectively. Green lines denote biomass burning ratios derived from the MODIS "hotspot" inventory during March 2006 and red line denotes best fit of the MCMA grid cells.

The satellite thermal anomaly data indicated many large fires occurred close to Mexico City during March 2006. Most of those fires were located along the mountain ridge just east of Mexico City (Fig. 1d). As indicated by Table 3, PM from biomass burning during this month is estimated to be larger than the annual emissions in Mexico City. This comparison, however, does not account for SOA formation, which is proportionally much larger from the urban emissions (Volkamer et al., 2006; Yokelson et al., 2007) and the possible overestimation of biomass burning emission ratios as discussed later and also by Aiken et al. (2009).

Scatter plots of POA and EC emissions versus those of $\mathrm{CO}$ over central Mexico for both anthropogenic and biomassburning sources are shown in Fig. 2. Over Mexico City, CO emission rates are well correlated with emission rates of POA and EC. The slope of $3.29 * 10^{-3}$ kilogram of urban POA per kilogram of CO from the entire MCMA inventory is similar to values estimated for other urban areas (Zhang et al., 2005; Docherty et al., 2008), but is 30-75\% lower than the values of 4.3-5.7 $\times 10^{-3}$ observed in ambient air at T0 during 2006 and at CENICA during 2003 (Dzepina et al., 2007; Aiken et al., 2009). Outside of Mexico City, emissions of POA and $\mathrm{EC}$ are relatively higher when compared with $\mathrm{CO}$ and there is more scatter. The differences between the two inventories are consistent with the total emissions listed in Table 3. The implications of the differences in the emission inventories on CO, EC, and POA predictions will be described later.

Recently Christian et al. (2009) suggested that trash burning at municipal landfills could be responsible for about $29 \%$ of the $\mathrm{PM}_{2.5}$ present in the urban Mexico City area. However, their estimate has a high uncertainty, since it is based on extrapolating measurements from four short-term trash burning events and the use of antimony (chemical symbol $\mathrm{Sb}$ ) as a tracer for trash burning. Querol et al. (2008) also attributed their measurements of $\mathrm{Sb}$ in Mexico City partic- ulates to a road traffic source, specifically abrasion of motor vehicle brake pads, consistent with a large literature on this source (e.g. Thorpe and Harrison, 2008; Amato et al., 2009). Insufficient activity information (e.g., frequency, duration, location, timing, etc.) is available to modify existing emissions inventories to include trash burning as a potential source of $\mathrm{PM}_{2.5}$.

\section{Results}

Even though a wide range of trace gases and particulates are included in the model, this study focuses on parameters useful to evaluate the simulated transport and mixing of POA over central Mexico. Inorganic particulate matter (i.e. $\mathrm{SO}_{4}$, $\mathrm{NO}_{3}, \mathrm{NH}_{4}$, dust) will be described in a subsequent study. The predicted POA will provide information needed to assess the overall magnitude of organic matter emission estimates (the largest component of total particulate matter emissions) from anthropogenic and biomass burning sources.

We first describe the performance of the model in simulating the circulations and boundary layer depth over central Mexico, since transport and mixing processes will directly affect the predicted spatial distribution of particulates. Predictions of $\mathrm{CO}$ are then evaluated to further assess simulated transport and mixing. The reactions associated with $\mathrm{CO}$ are very slow, thus $\mathrm{CO}$ can be treated as a passive scalar for the time scales in this study. Another passive scalar, EC, is evaluated because the sources of EC are similar to those of organic matter. Finally, predictions of primary organic aerosols are evaluated using components of organic matter derived from PMF analysis at the surface and aloft. All particulate concentrations in this paper are for ambient conditions, rather than at standard temperature and pressure (STP).

\subsection{Winds and boundary layer depth}

The overall meteorological conditions during MILAGRO are described in Fast et al. (2007) and de Foy et al. (2008). Near-surface winds over the central Mexican plateau are influenced by interactions between the heating and cooling associated with terrain variations and the larger-scale synoptic flow. Because Mexico City is located in a basin, the complexity of the local meteorology affects the transport and mixing of trace gases and particulates directly over their emission sources before they are transported downwind.

Several studies have assessed the performance of mesoscale models in simulating near-surface winds and boundary layer structure over Mexico City (e.g. de Foy et al., 2006; Fast and Zhong, 1998; Jazcilevich, et al., 2003). While there are difficulties simulating the details of the near-surface winds at specific locations and times, mesoscale models usually capture the primary thermally-driven circulations and their interactions that are observed, such as diurnally-varying upslope and downslope flows, northerly daytime flow into 

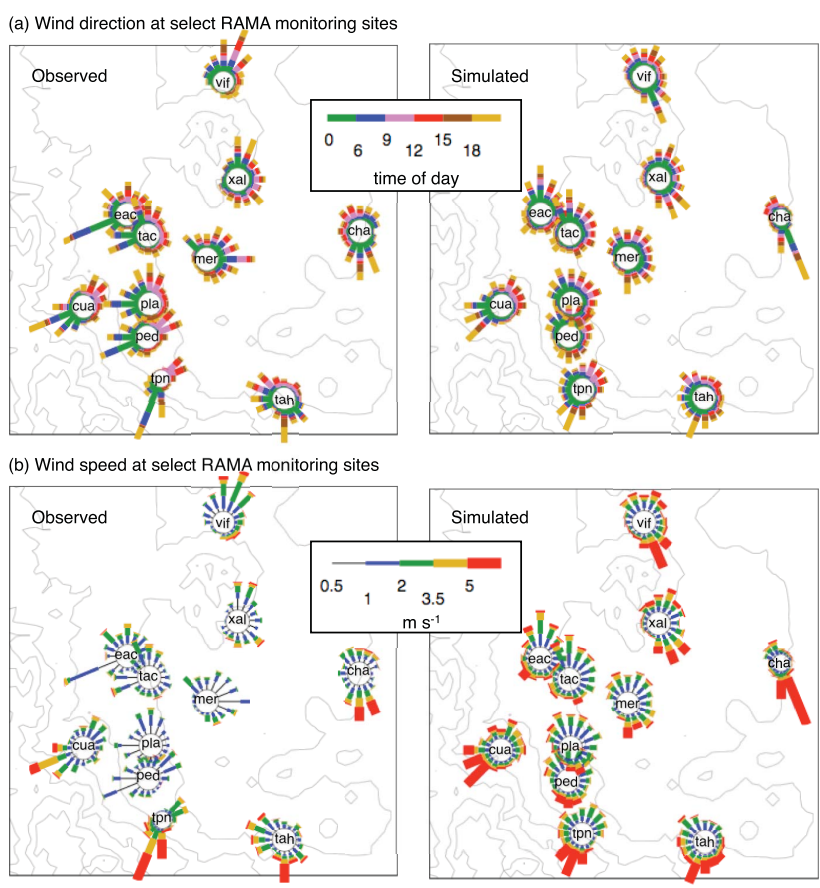

Fig. 3. Observed and predicted wind roses by (a) time of day (UTC) and (b) wind speed within 22.5 degree wind direction intervals during MILAGRO between 6 and 30 March for selected RAMA stations. Black lines denote terrain contours at $250 \mathrm{~m}$ intervals.

the basin, afternoon southerly gap winds through the southeastern end of the basin, and propagating density currents that bring in cool moist air from the coastal plain into the basin late in the afternoon.

Wind roses are employed in Fig. 3 to summarize the observed and predicted winds between 6 and 30 March at select RAMA operational monitoring stations. Inspection of individual time series of wind speed and direction (not shown) indicated that the simulated circulations were often qualitatively consistent with the observations. For example, the simulated north to northeasterly afternoon winds were similar to the observations (Fig. 3a). During the late afternoon, the model tended to over-predict the extent of the gap flow to the XAL and VIF stations as it propagated over the basin. While the winds were predicted reasonably well over the eastern side of the basin at the CHA station, the model propagated this southerly flow over the XLA and VIF stations that usually had northerly winds during the late afternoon. At night, the model produced downslope westerly flows that were observed at CUA; however, the simulated downslope flows did not propagate a few kilometers farther into the basin as observed after midnight at EAC, TAC, PLA, PED, and TPN. The simulated wind speeds were frequently larger than observed over the city center because heat, moisture, and momentum fluxes computed by the surface layer parameterization depend on similarity theory and a single roughness length for urban grid cells. A more complex urban canopy parameterization is required to create additional drag and that would reduce the simulated near-surface wind speeds. WRF does have an urban canopy, but databases that employ Mexico City buildings are still being developed. Surface wind measurements in an urban area are not likely to be representative over a large area, so some caution is needed when comparing observed and simulated quantities at specific locations.

Simulating the details of near-surface winds in areas of complex terrain and urban areas is still challenging for mesoscale models; however, model performance is much better aloft. An example of the simulated winds at the T1 and Veracruz sites compared with radar wind profiler measurements is shown in Fig. 4. Since the model employs the radar wind profiler measurements in the data assimilation scheme, it is not surprising that the simulated multi-day variations in the winds are very similar to the observations. For example, the winds at T1 between 9 and 11 March and 18 and 20 March are associated southwesterly flow ahead of troughs located over western Mexico that are strong enough to suppress local diurnal variability. At Veracruz, the most prominent feature is the passage of cold surges on 14, 22, and 23 March that bring strong northerly flows over the coast of the Gulf of Mexico. These flows occur below the height of the plateau and have a small impact on the winds over central Mexico.

Figure 5 is an example of an independent evaluation of the large-scale wind fields in which the predictions are compared with measurements from three aircraft on March 19 that are not employed by the data assimilation scheme. The aircraft flew at various altitudes: $0-5.5 \mathrm{~km}$ MSL for the G-1 and C130 , and $0-11 \mathrm{~km}$ MSL for the DC-8. The simulated winds are consistent with the measurements over the largest spatial scales associated with the C-130 and DC- 8 aircraft. Somewhat larger differences between the observed and simulated southwesterly winds occurred along the G-1 flight path just downwind of Mexico City. The wind speed correlation coefficients for the G-1, C-130, and DC-8 flights are 0.45, 0.70, and 0.89 , respectively. These results suggest that the model captures the overall synoptic scale flows well, but some uncertainties in the simulated local variability of the winds over the central Mexican plateau are associated with the interaction of the synoptic and thermally driven flows.

The continuous measurements of boundary layer (BL) depth at the T0, T1, and $\mathrm{T} 2$ sites can be used to assess the simulated depth of vertical mixing that will affect the dispersion of primary trace gas and particulate emissions. An example of the variation in the observed and predicted BL depth at T1 between March 17 and 23 is shown in Fig. 6a. Observed BL depths were obtained from radar wind profiler and lidar measurements as described by Shaw et al. (2007) and there may be uncertainties in the observed BL depth as much as a few hundred meters. The simulated magnitude and multi-day variations in BL depth were similar to the measurements. Observed and simulated BL depths on 17 March 

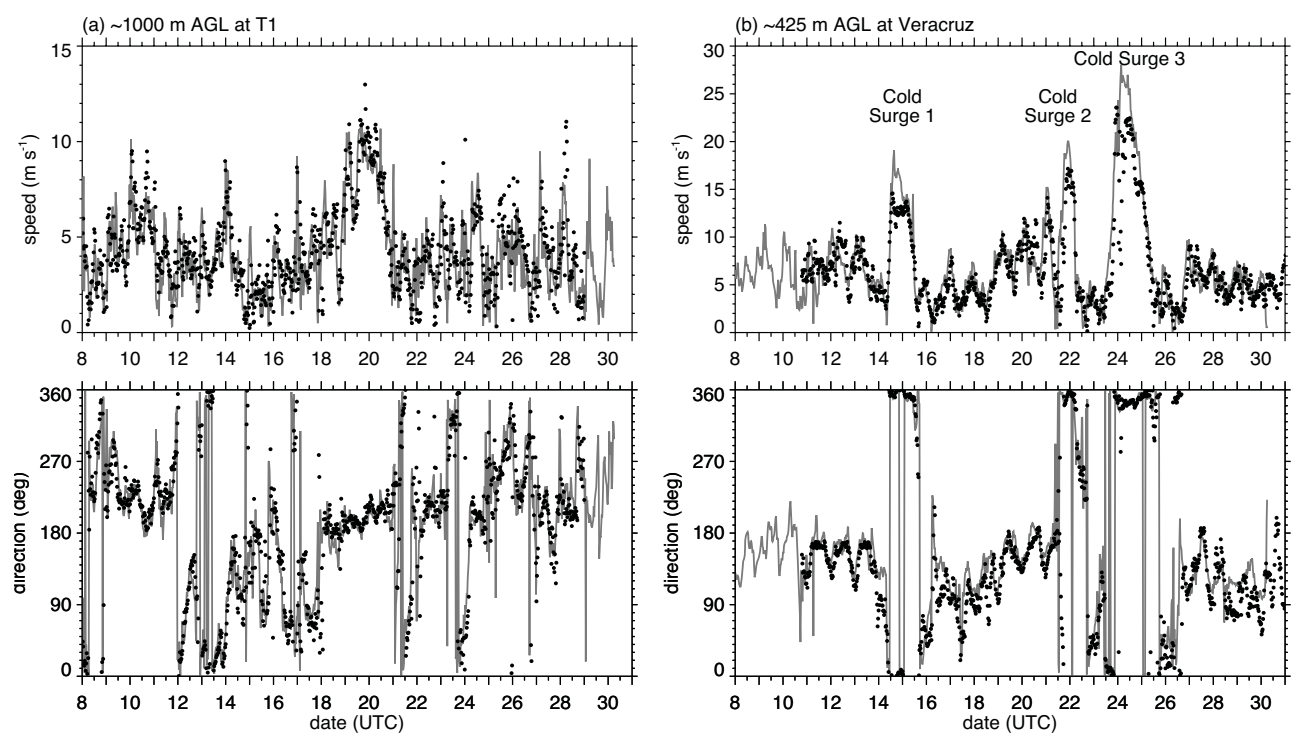

Fig. 4. Observed radar wind profiler wind speed and direction (dots) and predicted wind speed and direction (lines) at (a) T1 and (b) Veracruz, where UTC $=$ local standard time $+6 \mathrm{~h}$.
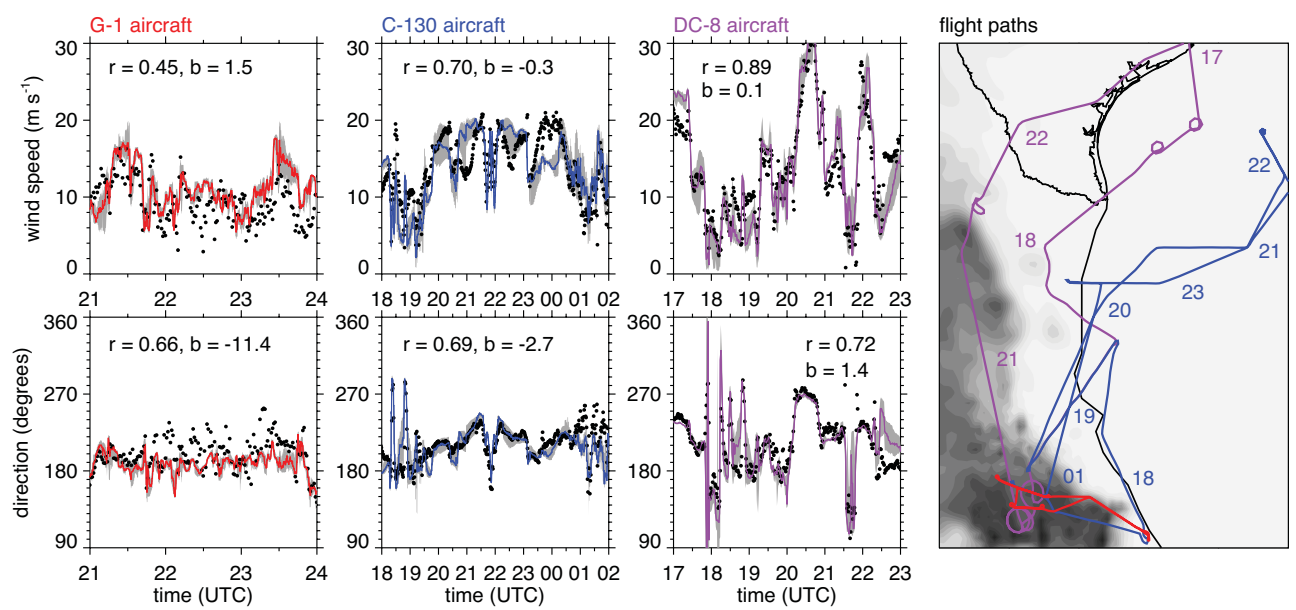

Fig. 5. Observed and predicted wind speed and direction along the G-1, C-130, and DC-8 flight paths on 19 March where gray shading denotes predicted values within one grid cell surrounding the aircraft position. Panel on right depicts the flight paths for each aircraft along positions at select times for the C-130 and DC- 8 aircraft.

were as high as 4.3 and $3.8 \mathrm{~km}$ AGL, respectively, while observed and simulated BL depths on 19 March were as high as 1.8 and $2.3 \mathrm{~km}$ AGL, respectively. There are differences in the rate of BL growth on some days, such as 20 March in which the simulated BL grew too quickly between 16:00 and 20:00 UTC (10:00-14:00 LT). The YSU scheme in version 3 of WRF also had a tendency to collapse the afternoon BL too quickly, such as on 18 March. The typical differences between the observed and simulated BL depth can also be seen by examining the mean and range of BL depths over the entire field campaign at the $\mathrm{T} 0, \mathrm{~T} 1$, and $\mathrm{T} 2$ sites shown in Figs. $6 \mathrm{~b}, 6 \mathrm{c}$, and $6 \mathrm{~d}$, respectively. The simulated BL growth is similar to the observations until about 20:00-21:00 UTC
(14:00-16:00 LT), but the tendency to collapse the BL too quickly occurred at all sites. It must be noted that radar wind profilers and lidars have difficulty detecting shallow stable layers that develop around sunset; therefore, the reported BL depths are really the vertical extent of mixing in a decaying residual layer during the transition between day and night.

\subsection{Carbon monoxide}

We next examine variations in carbon monoxide (CO) to evaluate the impact of simulated winds and BL depth during MILAGRO on the transport and mixing of trace gases in the region. 

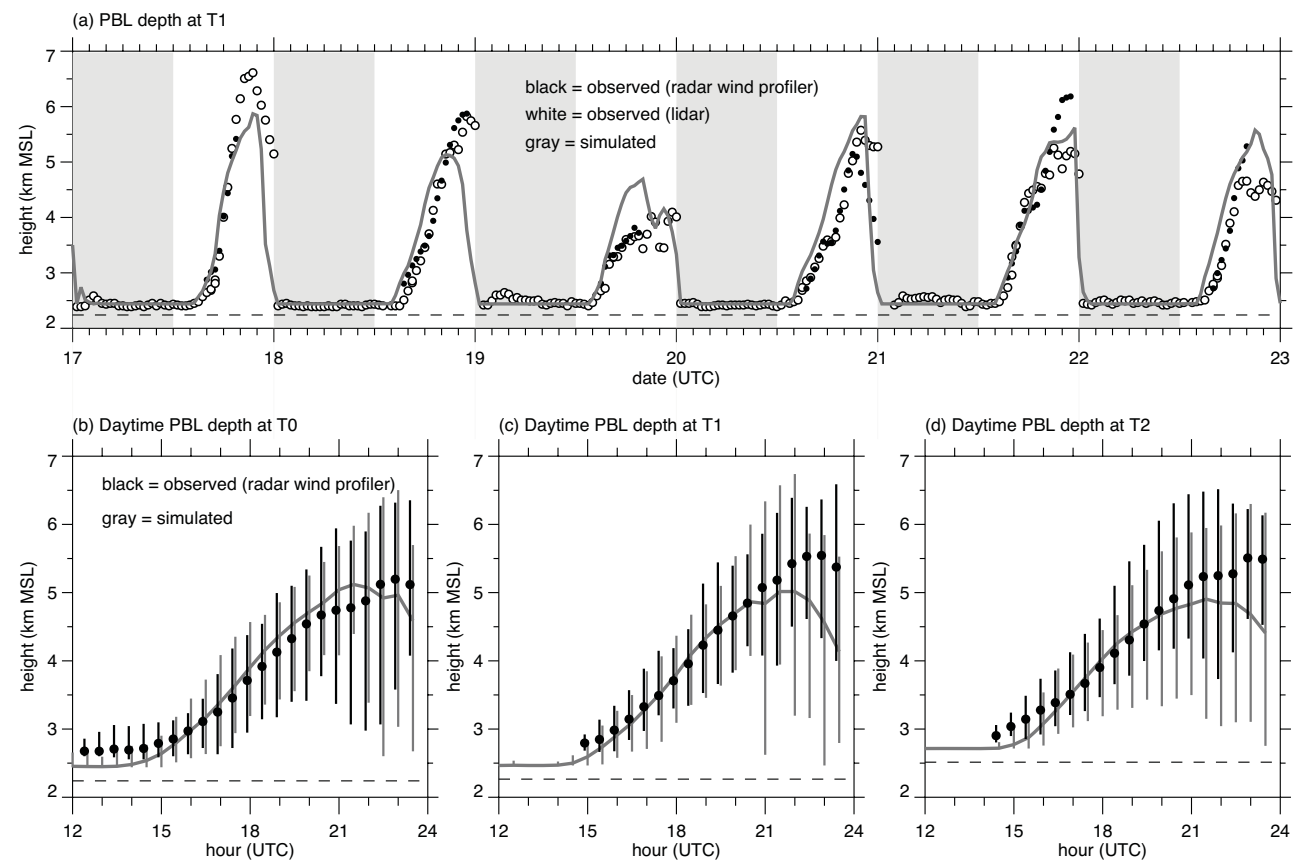

Fig. 6. (a) Observed (dots) and simulated (line) boundary layer depth at T1 between 17 and 23 March. Average daytime boundary layer height and range of values during the field campaign at the (b) T0, (c) T1, and (d) T2 sites. Dashed lines denote the elevation of each site.
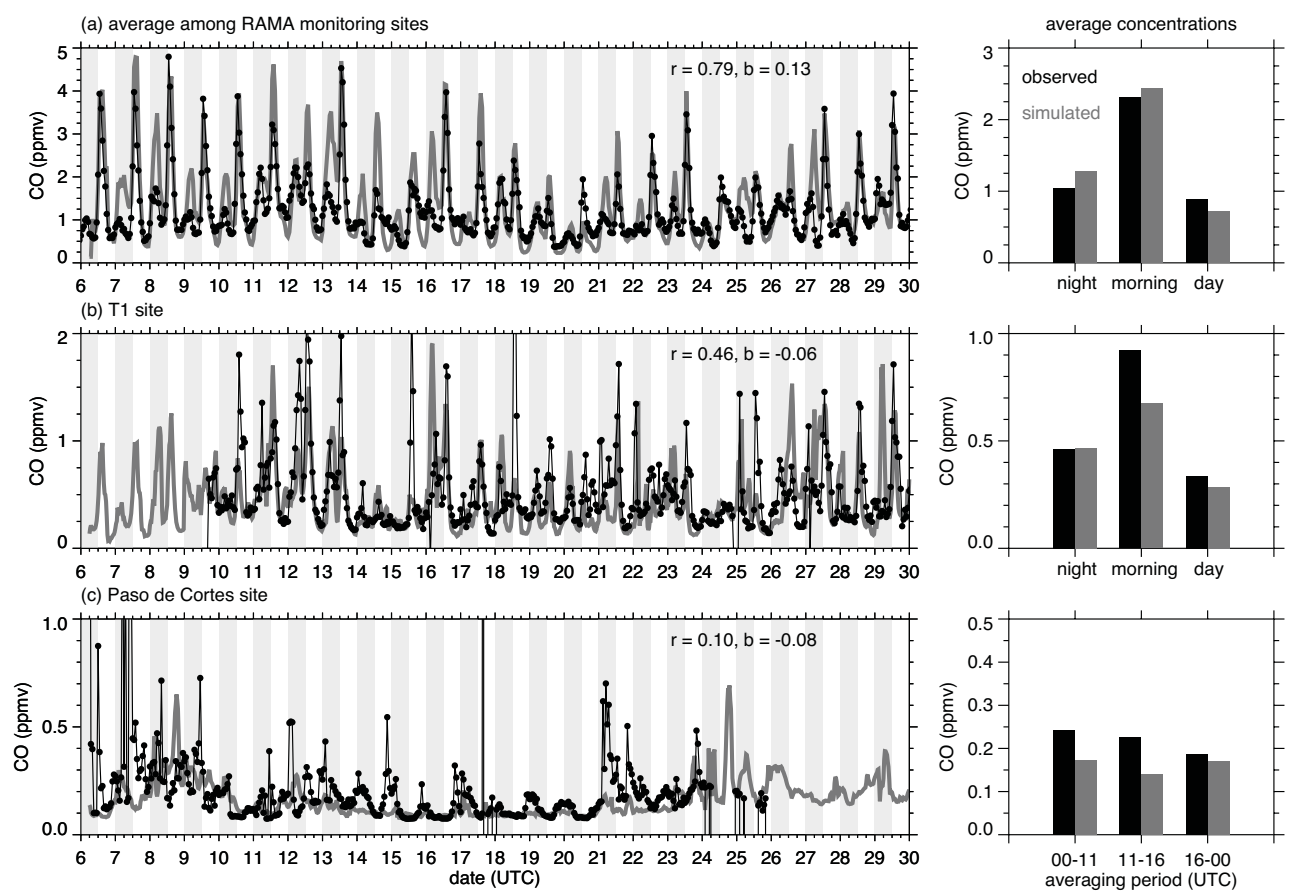

Fig. 7. Observed (dots) and simulated (gray line) (a) CO mixing ratio averaged among 25 RAMA operational monitoring stations within the Mexico City basin and CO mixing ratio at the (b) T1 site and (c) Paso de Cortes site. Correlation coefficient and mean bias denoted by $\mathrm{r}$ and b, respectively. The panels on the right are averages the observed (black) and simulated (gray) values during night (18:00-05:00 LST), morning (05:00-10:00 LST), and daytime (10:00-18:00 LST) periods. 
The observed and simulated diurnal variation in the average $\mathrm{CO}$ computed among the RAMA operational monitors in Mexico City is shown in Fig. 7a. The model reproduced the magnitude and timing of $\mathrm{CO}$ reasonably well with a correlation coefficient of 0.79 . Observed and simulated peak values occurred just after sunrise and are associated with the morning rush-hour traffic and shallow BL depths. Simulated CO was somewhat too high at night that is likely the result of an underestimation of BL mixing during some nights. While there were no direct continuous measurements of BL depth at night over the city, we suspect that the heating and roughness elements associated with buildings would enhance vertical mixing (e.g. Sarrat et al., 2006) not presently accounted for in the model. Inspection of potential temperature profiles obtained from radiosondes launched several kilometers southwest of T0 at 06 UTC (midnight) indicate that the nocturnal boundary layer could be as high as $500 \mathrm{~m}$ AGL on a few nights (not shown); however, a $200 \mathrm{~m}$ minimum nocturnal boundary layer depth was employed by the model based on lidar backscatter data at T1 (Fig. 7a). Therefore, the effect of vertical mixing in the city could be about a factor of two too low at times during the night. The $\mathrm{CO}$ values are also averaged for nighttime periods between 00:00 and 11:00 UTC (18:00-05:00 LT), morning periods between 11:00 and 16:00 (05:00-10:00 LT) and afternoon periods between 16:00 and 00:00 UTC (10:0-18:00 LT). Simulated CO was $\sim 20 \%$ higher that observed when averaged among all the nighttime periods. The simulated errors in $\mathrm{CO}$ were less during the day, with morning values being $\sim 7 \%$ higher than observed.

The consistency of the monitoring data and simulated $\mathrm{CO}$ suggests that the overall emission estimates of $\mathrm{CO}$ over the city are reasonable. However, there is evidence to suggest that the diurnally varying emission rates may be off somewhat because $\mathrm{CO}$ was somewhat lower than observed during the afternoon. The tendency of the model to collapse the boundary layer $1-2 \mathrm{~h}$ before sunset should have produced a positive bias in $\mathrm{CO}$.

The observed and simulated CO just outside of the city at the T1 site is shown in Fig. 7b. While the model qualitatively captured the magnitude and temporal variations in the observed CO, errors in simulated $\mathrm{CO}$ are somewhat larger than over the city as indicated by the lower correlation coefficient of 0.46 . When the results are averaged over the three time periods, it is evident that most of the errors are associated with the under-predictions during the morning period between 11 and 16 UTC (05:00-10:00 LT). This would suggest that BL depths would be over-predicted, but this is not supported by Fig. 6. We suspect that uncertainties in the emission inventories contribute to uncertainties in predicted $\mathrm{CO}$ at this location. Rapid changes in urban growth at the edge of the city and/or traffic along the highway just to the south of T1 during the morning rush hour period may not be represented well.

At the Paso de Cortes site (Baumgarder et al., 2009), located $\sim 1.8 \mathrm{~km}$ above the basin, the model captured much of the multi-day variations in $\mathrm{CO}$ (Fig. 7c). However, the simulated peak values were too low. Peak $\mathrm{CO}$ mixing ratios ranged between 0.4 and $1.0 \mathrm{ppm}$ on twelve days between 6 and 24 March, but simulated CO exceeded 0.4 ppm only on one day. The observed and simulated peaks occurred during both daytime and nighttime periods, but they are not well correlated. The $\mathrm{CO}$ averages do not show the same diurnal variations in the city, as expected at this remote site. The lower CO/EC anthropogenic emission ratios outside of Mexico City (Fig. 2) likely contributed to the negative bias in the predicted CO. Additionally, the $3 \mathrm{~km}$ horizontal grid spacing may be insufficient to represent local terrain-induced flows along the mountain ridge and subsequently affects the transport and mixing of smoke plumes from nearby fires (Fig. 1d).

Predictions of $\mathrm{CO}$ further downwind were also evaluated using data averaged over 10-s intervals from the research aircraft. An example of the spatial and temporal variations on March 19 is shown in Fig. 8, the same time period as the winds shown in Fig. 5. Close to the city, the simulated CO was similar to the measurements along most of the G-1 flight path (Fig. 8a) with a correlation coefficient of 0.63. Simulated $\mathrm{CO}$ was higher than observed during four periods in which the aircraft passed over the east side of the Mexico City valley where a large number of fires occurred. Several factors could have contributed to the over-prediction in $\mathrm{CO}$ at this location including estimates for biomass burning that were too high, estimates of the peak burning rate that is assumed to occur at 20:00 UTC (14:00 LT) every afternoon, and the simulated vertical mixing that may not loft the $\mathrm{CO}$ plume to the correct altitudes. Observed and simulated BL height over the city at the time of the G-1 flight was $\sim 4 \mathrm{~km}$ MSL (Fig. 6a) and the aircraft was flying just below this altitude. Measurements of potential temperature also suggest the aircraft was within the BL at this time. While the simulated BL depth is reasonable, the model does not account for enhanced vertical mixing associated with the higher temperatures associated with fires that could account for a portion of the over-prediction in $\mathrm{CO}$ close to the location of the fires.

Further downwind along the C-130 flight path (Fig. 8b) the simulated variations in CO between the plateau and the Gulf of Mexico qualitatively similar to the measurements, with a correlation coefficient of 0.58 that was higher than along the G-1 path. The differences are associated primarily with the background mixing ratios and specific biomass burning plumes. The simulated background values of $\sim 80 \mathrm{ppb}$ were about $20 \mathrm{ppb}$ higher than observed, and are likely due to background values obtained from the MOZART model. The peak in simulated CO of $\sim 600 \mathrm{ppb}$ at 01:00 UTC (19:00 LT) was also associated with biomass burning plumes just northeast of Mexico City and was 350 ppb higher than observed. Along the DC-8 flight path (Fig. 8c) the observed and simulated CO increased between 17:00 and 19:00 UTC (11:00 and 13:00 LT) as the aircraft approached Mexico City. Peak values were observed directly over Mexico City, but the simulated values were higher than observed for a short period of 


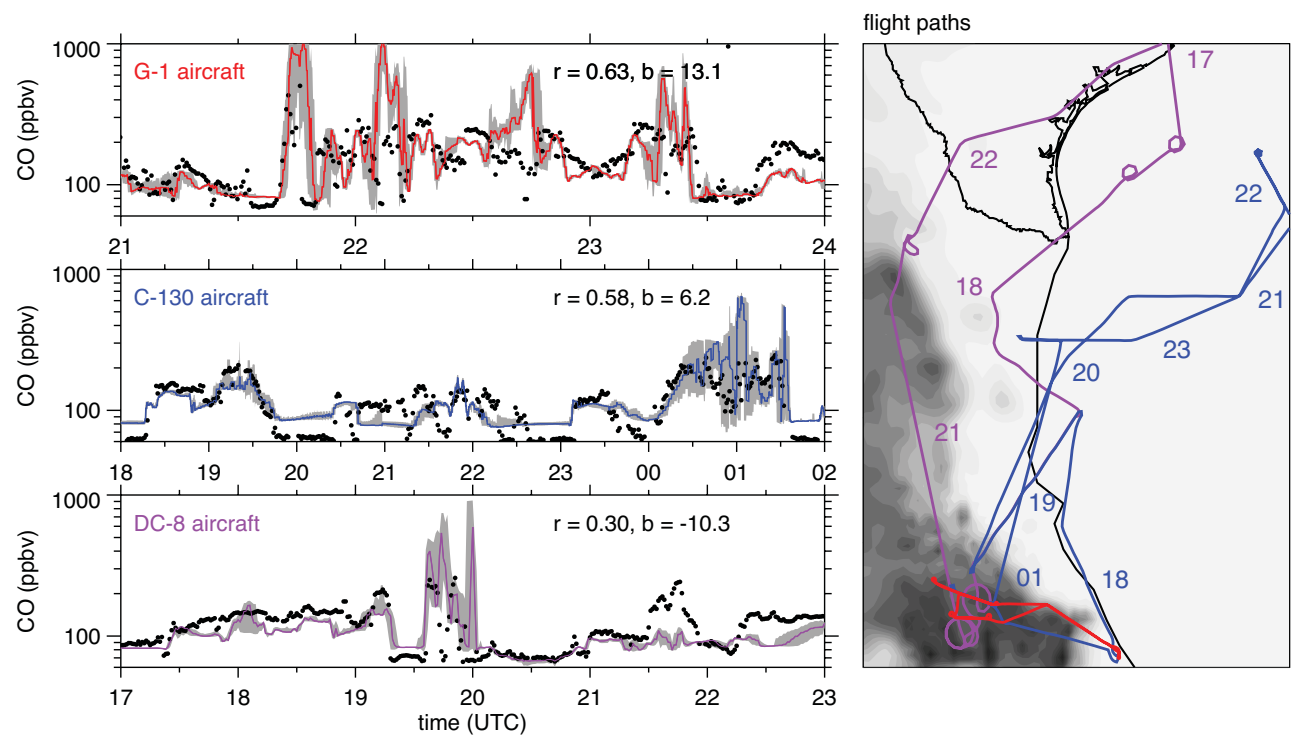

Fig. 8. Observed (dots) and simulated (lines) CO mixing ratio along three aircraft flight paths on 19 March where gray shading denotes predicted values within one grid cell surrounding the aircraft position. Correlation coefficient and mean bias denoted by $r$ and $b$, respectively. Panel on right depicts the flight paths for each aircraft along positions at select times for the C-130 and DC-8 aircraft.

time. Both the observed and simulated $\mathrm{CO}$ was low between 20:00 and 21:00 UTC (14:00-15:00 LT) when the aircraft ascended to high altitudes northwest of Mexico City, but the simulated $\mathrm{CO}$ was lower than observed closer to the surface over Texas when the aircraft was flying back to Houston.

A summary of the statistical performance of the simulated $\mathrm{CO}$ using percentiles, correlation coefficient $(r)$, and mean bias (b) for all G-1, C-130 and DC-8 flights is shown in Fig. 9. A much larger range for both the observed and simulated percentiles is seen in for G-1 aircraft since it usually flew in the immediate vicinity of the Mexico City and was frequently within the anthropogenic plume. The percentiles show that the model overestimated the measured range of $\mathrm{CO}$ on some days and underestimated the range of $\mathrm{CO}$ on others. Both the observed and simulated percentiles were lower for the C-130 aircraft since a large fraction of the flight time was spent downwind of Mexico City, and the simulated range of $\mathrm{CO}$ was higher and lower than observed depending on the day. In contrast, the simulated range of $\mathrm{CO}$ along the DC-8 flight paths was usually less than observed. When averaged among all the aircraft, the percentiles were very similar to the measurements, mean values somewhat lower than observed with a correlation coefficient of 0.61 . The correlation coefficients that measure the skill in predicting the magnitude of $\mathrm{CO}$ in space and time ranged from 0.30 to 0.89 among the aircraft flights. The results shown in Fig. 9 suggest that the model adequately reproduced the overall transport and mixing of $\mathrm{CO}$ downwind of Mexico City, although there were occasional errors in space and time for the exact position of $\mathrm{CO}$ plumes and magnitude of smoke plumes.

\subsection{Elemental carbon}

Observed and predicted concentration of elemental carbon (EC) at the T0, T1, T2, and Paso de Cortes sites is shown in Fig. 10. The model performed the best at T0, the urban site located closest to the highest emission rates. The magnitude and temporal variation of the simulated EC was similar to the measurements with a correlation coefficient of 0.56 . The average values during nighttime periods between 00:00 and 11:00 UTC (18:00-05:00 LT) and afternoon periods between 16:00 and 00:00 UTC (10:00-18:00 LT) periods were predicted quite well over the period. However, simulated EC during the morning between 11:00 and 16:00 UTC (05:0010:00 LT) was significantly underestimated in contrast with CO predictions over the city (Fig. 7a). Since errors in BL depth will affect $\mathrm{CO}$ and EC similarly, one must conclude that differences are likely the result of greater uncertainties in EC emissions over the city. One factor could be the relative contribution of diesel vehicles at that time of day in the city, since the CO/EC ratios from the MCMA emission inventory was somewhat higher during the morning rush hours between 12:00 and 15:00 UTC (06:00-09:00 LT) than during the rest of the day.

EC predictions at the T1 site were nearly always lower than observed, although the correlation of 0.45 indicates that the simulated diurnal variation in EC was somewhat similar to the observations. As with $\mathrm{CO}$ at this site (Fig. 7b), the largest errors occurred during the morning hours and emission rates of EC may be more problematic at this location than in the city.

Both the observed and simulated EC were usually below $2 \mu \mathrm{g} \mathrm{m}^{-3}$ further downwind at the remote T2 site. Since the 


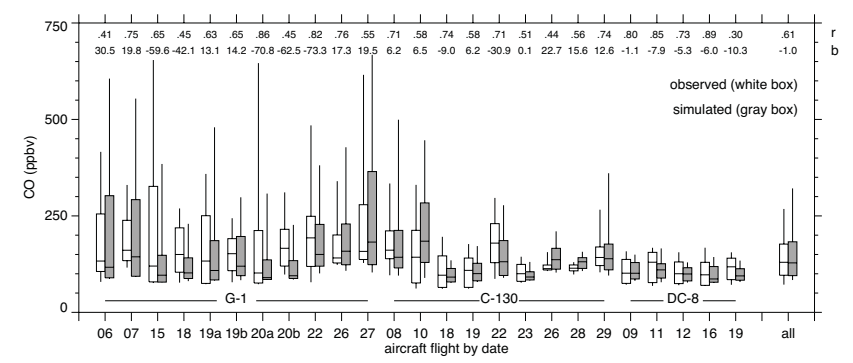

Fig. 9. Comparison of observed and simulated $\mathrm{CO}$ along the aircraft flight paths, where horizontal lines denote the median, boxes denote 25 th and 75 th percentiles, and vertical lines denote 10 th and 90th percentiles. Correlation coefficient (r) and mean bias (b) for each flight are included along the top. G-1 and C-130 values were obtained over domain 2 and DC-8 values obtained over domain 1 . (a) and (b) denote morning and afternoon flight periods for the G-1 aircraft.

T2 site is remote, the time series of EC indicates multi-day variations and short time scale fluctuations instead of the diurnal variations observed at the T0 and T1 sites. While it is likely that $\mathrm{T} 2$ is impacted by Mexico City emissions when the regional winds are southwesterly (e.g. higher EC concentrations between March 18 and 22), transport from Mexico City to T2 does not occur every day (Doran et al., 2008). Instead, EC observed at T2 is from dilute plumes originating from many urban and biomass burning sources. While simulating the exact timing of dilute plumes transported over T2 is challenging, the similarity of the observed and simulated average EC concentrations is nevertheless encouraging.

At the Paso de Cortes remote site, the model reasonably simulated the magnitude and temporal variations in EC prior to 23 March (Fig. 7c). The observed and simulated peaks in EC during the late afternoon on many days (e.g. 16 and 17 March) indicates that some time is required to transport Mexico City EC to this site and that the BL must be sufficiently high since the site located $\sim 1.8 \mathrm{~km}$ above the basin floor. After 23 March, the simulated EC is significantly higher than observed. Increased convective activity after the third cold surge on 23 March (Fast et al., 2007) likely led to increased vertical mixing and removal by wet deposition. While the model did produce more cloudiness over the region after 23 March, vertical mixing associated with convection and wet removal were underestimated.

The lower CO/EC anthropogenic emission ratios outside of Mexico City (Fig. 2) likely contributed to the negative bias in the predicted CO at the remote Paso de Cortes site. Both of these sites would be impacted by emissions from cities other than Mexico City during the field campaign, and changing the slope of the regional CO/EC emissions rates to be more like the MCMA inventory (Fig. 2) would improve predictions of both $\mathrm{CO}$ and $\mathrm{EC}$ at theses locations.

\subsection{Organic matter}

As described previously, the current version of MOSAIC includes only primary organic aerosols and does not treat SOA. Consequently, predictions of organic matter should be significantly underestimated when compared with the available measurements of total organic matter in the vicinity of Mexico City. If predicted organic matter is higher than observed, then one would conclude that the estimates of primary emissions of organic aerosols are too high because we have shown that transport and mixing is simulated reasonably well during the MILAGRO field campaign period. AMS data in conjunction with PMF analysis also provides a new tool to evaluate POA predicted over both urban and remote locations.

Examples of how PMF analysis can be used to evaluate POA are shown in Fig. 11, in which the time series of observed total organic matter, $\mathrm{HOA}, \mathrm{HOA}+\mathrm{BBOA}$, and OOA (Aiken et al., 2008, 2009) is compared with predicted POA at the T0 site on 15 and 20 March. Simulated POA is based on the sum of the mass in the first four model size bins (from 0.39 to $0.625 \mu \mathrm{m}$ ), since the number of particles with an estimated volume-equivalent diameter, $d_{v e}$ (DeCarlo et al., 2004), larger than $0.7 \mu \mathrm{m}$ observed by the AMS instrument was very low. Adding mass from the fifth model size bin (from 0625 to $1.25 \mu \mathrm{m}$ ) did not increase the simulated POA shown in Fig. 11 significantly.

The diurnal variation in HOA on 15 March (Fig. 11a) is similar to primary emissions (e.g. $\mathrm{CO}$ ) with the highest concentrations shortly after sunrise at the time of peak traffic activity and within a shallow boundary layer. HOA is reduced by vertical mixing as the convective boundary layer grows during the morning after 14:00 UTC (08:00 LT); however, concentrations are quite variable between 14 and 18:00 UTC (08:00-12:00 LT) as a result of light and variable winds that likely transport primary emissions over T0 from different parts of the surrounding urban area. HOA subsequently increases somewhat just before sunset as primary emissions build up within the shallow nocturnal boundary layer. In contrast, OOA increases during the late morning despite increased boundary layer vertical mixing, suggesting that a photochemical secondary process is responsible for the production of OOA. BBOA has the same temporal variation as HOA. There was only one fire reported in the vicinity of Mexico City on this day; therefore, BBOA likely represents dilute smoke from multi-day regional scale transport and many small-scale burning events within the city that cannot be detected by the MODIS hot-spot data.

The diurnal variation of simulated POA on this day was more consistent with HOA, although POA concentrations were higher than HOA concentrations most of the day. Emission rates that were too high, simulated ventilation of the basin that was too weak, and vertical mixing within the nocturnal boundary layer that was too weak could all explain the positive bias in organic aerosols. While the simulated boundary layer depth was similar to estimates from the radar wind 

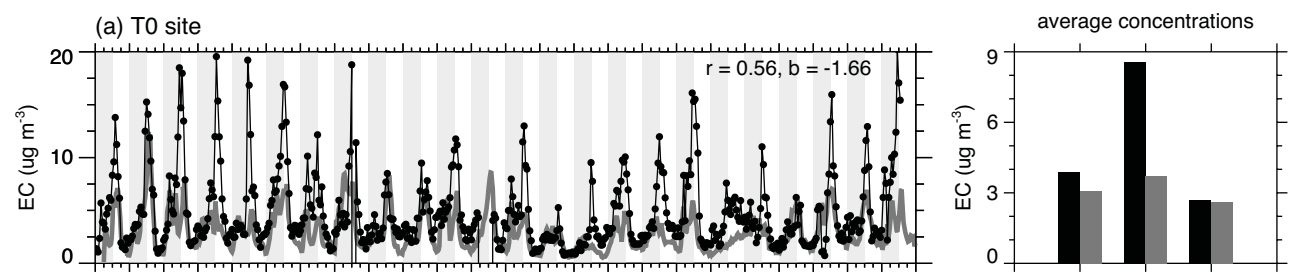

(b) T1 site
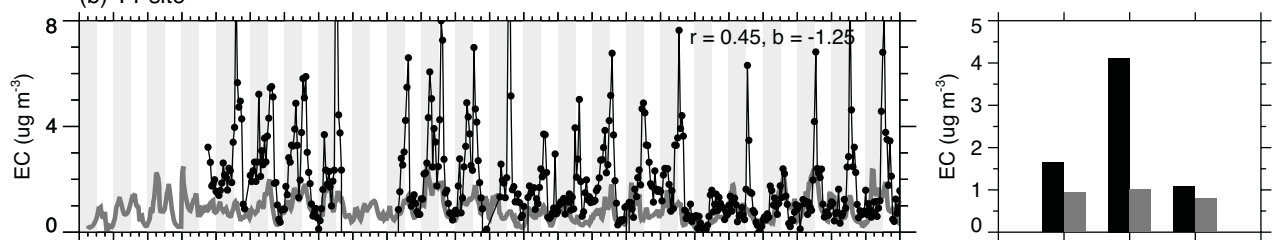

(c) T2 site
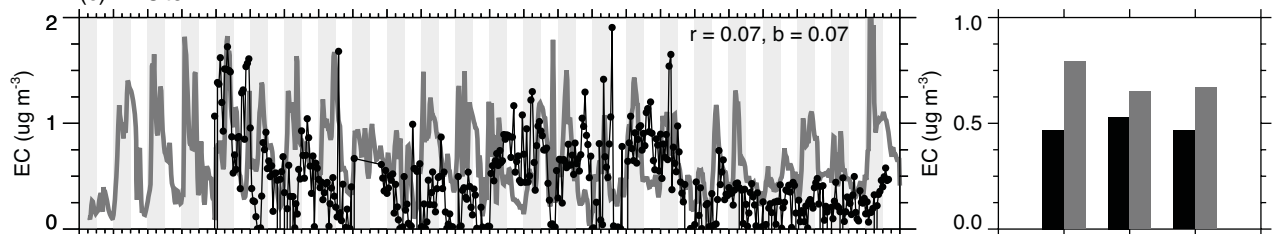

(d) Paso de Cortes site
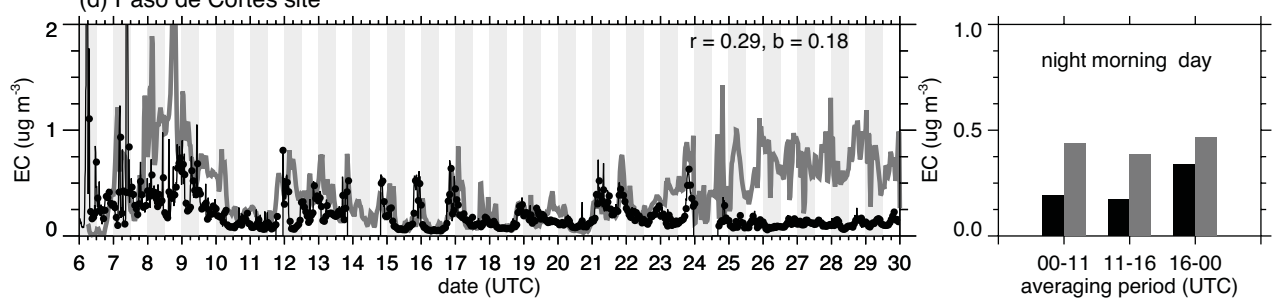

Fig. 10. Time series of observed (black) and modeled (gray) elemental carbon at the (a) T0, (b) T1, (c) T2, and (d) Paso de Cortes sites (left) and average concentrations during the night (18:00-05:00 LST), morning (05:00-10:00 LST), and daytime (10:00-18:00 LST) periods (right). Correlation coefficient and mean bias denoted by $r$ and $b$, respectively.

profiler at $\mathrm{T} 0$ during the day, the simulated nocturnal boundary layer depth was $200 \mathrm{~m}$ while the sounding launched several kilometers southwest of T0 at 06:00 UTC (midnight) 16 March indicated a neutral layer up to $500 \mathrm{~m}$ AGL. Thus, the model likely underestimated the amount of mechanical mixing associated with the urban canopy and/or the basin circulations. This would also explain why simulated $\mathrm{CO}$ mixing ratios that were also higher than observed that night (Fig. 7a)

In contrast with 15 March, observed organic aerosol concentrations during the afternoon of 20 March (Fig. 11b) were much lower and the temporal variations of HOA and OOA were not typical of the more frequently observed morning build up of primary emissions followed by increased boundary layer vertical mixing and photochemistry. Instead, relatively strong southwesterly ambient winds ventilated pollutants out of the basin to the north and kept afternoon concentrations relatively low. Observed HOA did have a sharp peak between 12:00 and 14:00 UTC (06:00-08:00 LT) in the morning because observed wind speeds from the radar wind profiler were less than $1 \mathrm{~m} \mathrm{~s}^{-1}$ within the shallow boundary layer (not shown) that likely permitted the build-up of primary emissions, but concentrations dropped rapidly as the boundary layer grew and near-surface winds became coupled with the stronger winds aloft. BBOA increases around sunset as a result of a smoke plume transported from a fire on the mountain ridge south of the city.

Simulated POA was similar to the sum of HOA+BBOA most of the day, except for a brief period shortly after sunrise. While the model captured the increase in organic aerosol associated with a smoke plume late in the day, it failed to capture the peak in anthropogenic organic aerosols between 12:00 and 14:00 UTC (06:00-08:00 LT). At this time nearsurface simulated wind speeds were between 2 and $3 \mathrm{~m} \mathrm{~s}^{-1}$ and consequently simulated POA concentrations as high as $9 \mu \mathrm{g} \mathrm{m}^{-3}$ were transported northeast of T0.

Predictions of POA have been compared with organic matter measurements from the available AMS and OC/EC data made at the T0, Pico Tres Padres, T1, T2, and Paso de Cortes sites as shown in Fig 12. Instead of showing the entire time series, mean diurnal variations of organic components are computed for the measurement period at each site. The diurnal variation of organic components over the entire field campaign period at T0 (Fig. 12a) is similar to the 15 March time series shown in Fig. 11a. Predicted POA has a magnitude 

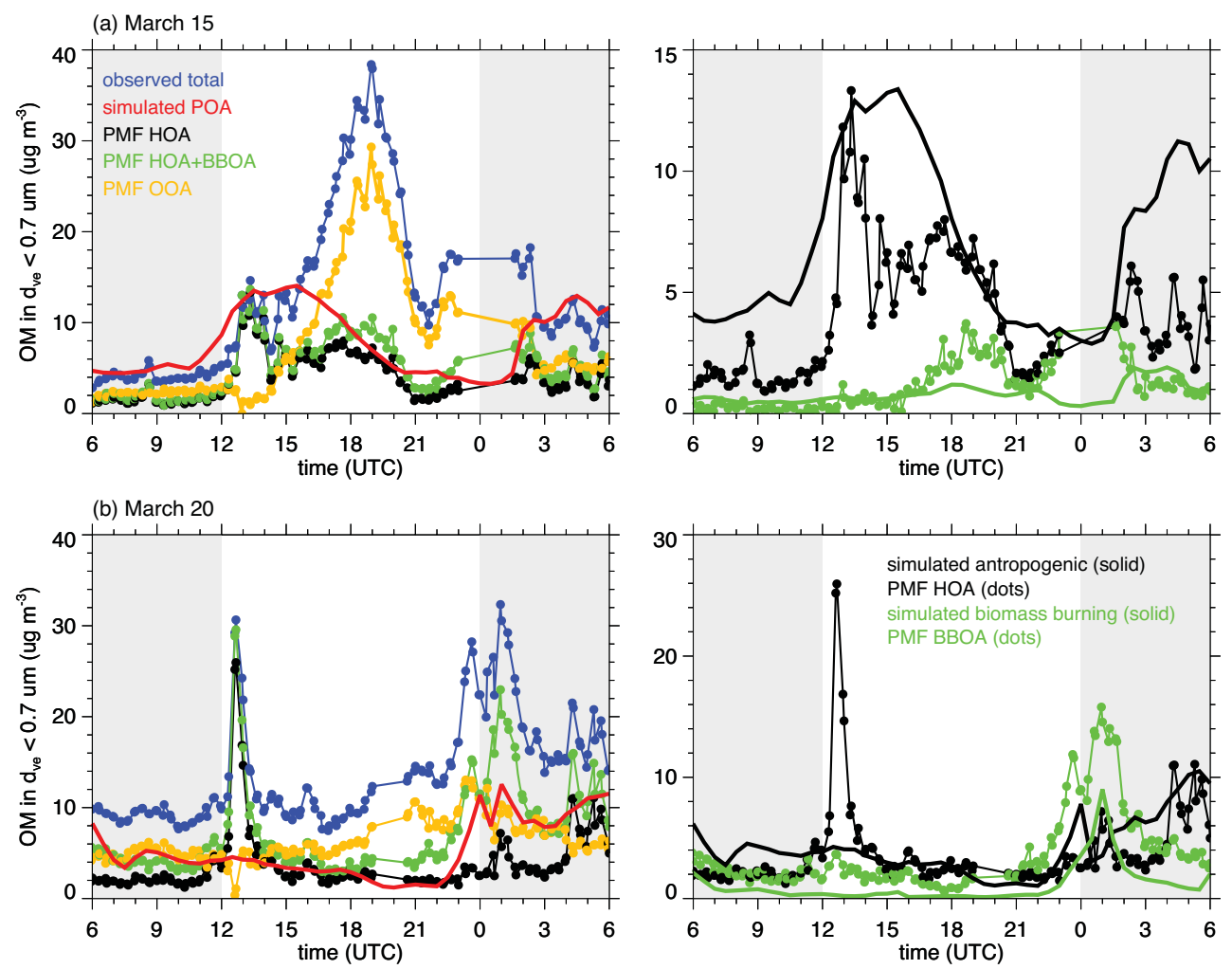

Fig. 11. Time series of observed and modeled average diurnal variations of total organic matter at the $\mathrm{T} 0$ site and the components of organic matter derived using the PMF analysis technique on (a) 15 March and (b) 20 March. Right panels depict simulated POA resulting from anthropogenic and biomass burning sources compared to HOA and BBOA, respectively. Most of the mass from the AMS instrument is assumed to be for particles with diameters less than $0.7 \mu \mathrm{m}$.
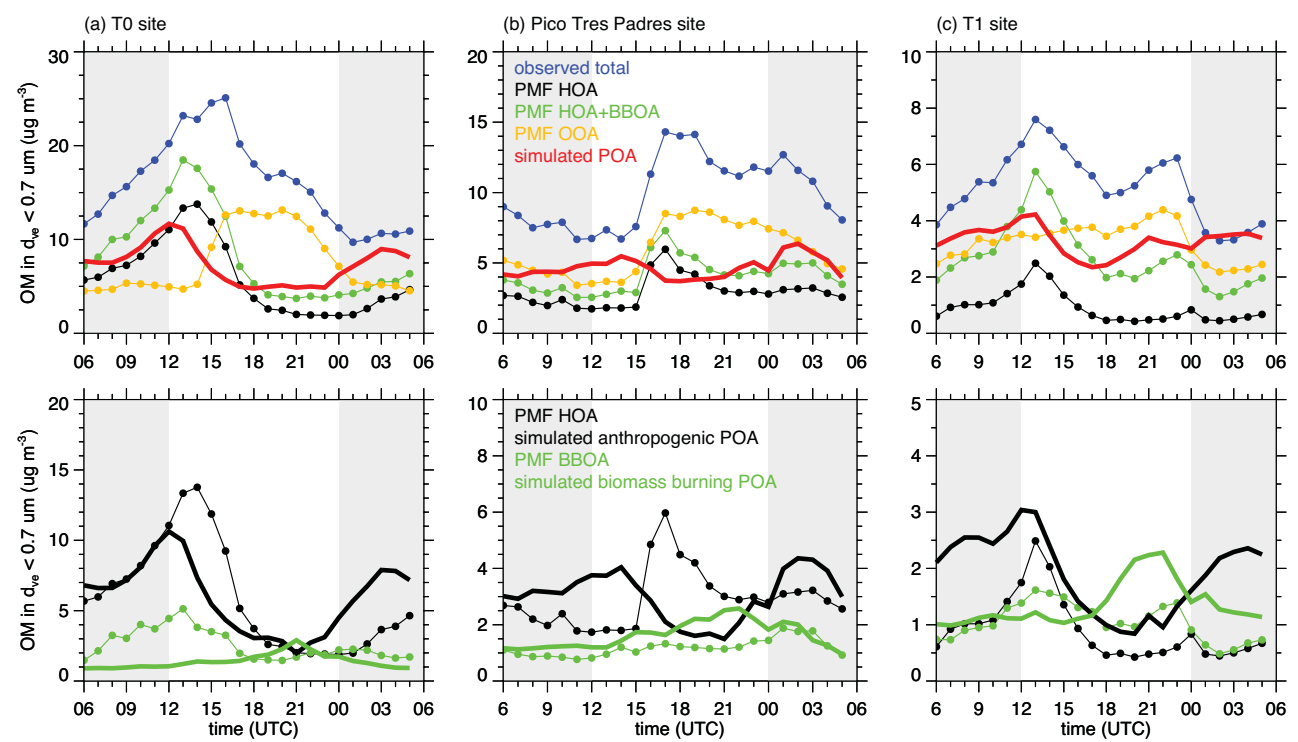

Fig. 12. Time series of observed, PMF components, and modeled average diurnal variations of organic matter at the (a) T0, (b) Pico Tres Padres, and (c) T1 sites. Bottom panels depict simulated anthropogenic and biomass burning POA compared with HOA and BBOA, respectively. 
and diurnal variation that is more consistent with $\mathrm{HOA}$ or $\mathrm{HOA}+\mathrm{BBOA}$, depending on the time of day, than with total organic matter. The simulated peak in POA occurred one or two hours earlier than the peaks in HOA + BBOA and HOA, respectively. The consistent over-prediction of POA at night may be attributed to insufficient vertical mixing within the nocturnal boundary layer in the city.

PMF analysis was also available from the AMS instruments at the Pico Tres Padres (Fig. 12b) and T1 (Fig. 12c) sites. As with T0, the daily averaged predicted POA was between daily averaged HOA and HOA+BBOA concentrations. While the predicted diurnal variations in POA are consistent with variations in $\mathrm{HOA}$ at $\mathrm{T} 0$, the diurnal variation in predicted POA and measured HOA differ more at Pico Tres Padres and T1. At Pico Tres Padres, the most likely explanation for the discrepancy is that the $3-\mathrm{km}$ grid spacing in the model cannot adequately resolve the local slope flows and boundary layer evolution at the mountaintop sampling site. The observations show a dramatic increase in organics at 15:00 UTC (09:00 LT), which occurs when the convective boundary layer grows above the altitude of the mountain (Herndon et al., 2008). Smoothing of the topography associated with the $3-\mathrm{km}$ grid spacing produced a mountain-top elevation of $2500 \mathrm{~m}(\sim 400 \mathrm{~m}$ lower than the actual elevation); therefore, the simulated atmosphere was not fully decoupled from Mexico City emission sources at night. At the T1 site, the model produced a peak in POA at 13:00 UTC (07:00 LT) similar to the measurements of HOA and HOA+BBOA. But the subsequent decrease in simulated POA reversed at 17:00 UTC (11:00 LT) instead of continuing to decrease for four more hours during the afternoon. As discussed previously with $\mathrm{CO}$ and EC, there are likely uncertainties in the local emissions that may contribute to errors on POA at this site, including brick kilns (Christian et al., 2009) and other local sources.

Comparisons of predicted POA and total organic matter from the OC/EC instrument at the T2 site and the AMS instrument at the Paso de Cortes site is shown in Fig. 13a and b, respectively. Predicted POA concentrations were usually less than half the observed total organic matter at both sites. Increases in observed afternoon total organic matter is likely the result of SOA formation as anthropogenic particulates are transported over both of these sites. The increase in observed afternoon total organic matter is more dramatic at Paso de Cortes than at T2 because the Paso de Cortes site is located at a much higher elevation. Measurements at Paso de Cortes during the night are likely to be more representative of the free atmosphere. As the convective boundary layer grows during the morning the site is entrained into the convective boundary layer that contains much higher concentrations of anthropogenic particulates.

The range of total observed organic aerosol, HOA, HOA+BBOA, and predicted POA at the T0, Pico Tres Padres and $\mathrm{T} 1$ sites is depicted in terms of percentiles, biases, and correlation coefficients in Fig. 14. The median and range
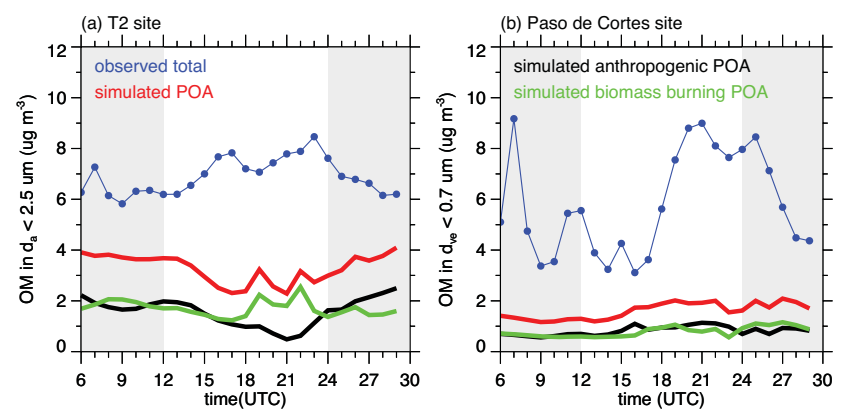

Fig. 13. Time series of observed and modeled average diurnal variations of organic matter at the (a) T2 site using Sunset Laboratory EC/OC data and the (b) Paso de Cortes site using Aerodyne Aerosol Mass Spectrometer (AMS) data. PMF components not currently available at the Paso de Cortez site.
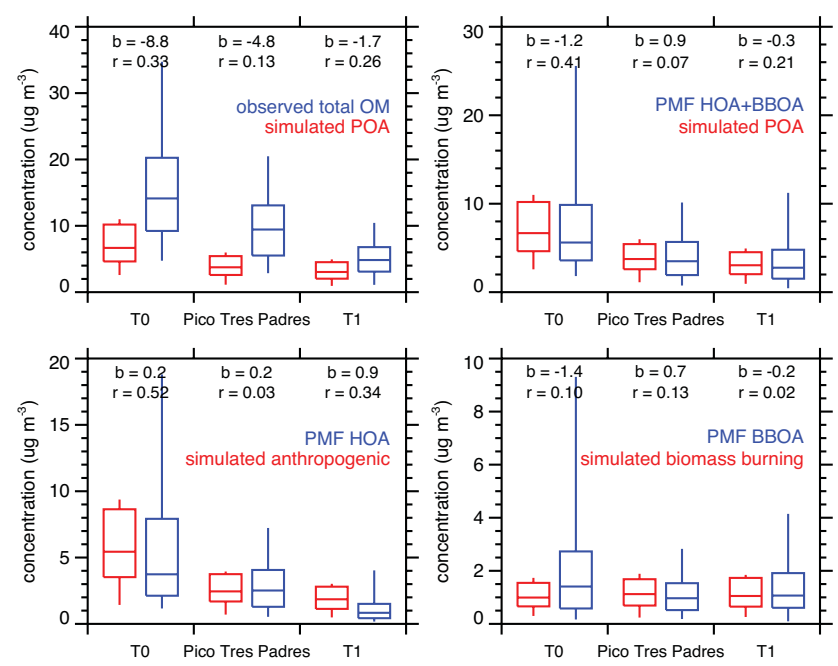

Fig. 14. Box-and-whisker plots of observed organic matter, PMF components, and simulated primary organic matter at the T0, Pico Tres Padres, and T1 sites during the field campaign, where the box denotes the range of the 25 th and 75 th percentiles, the vertical lines denote the 5th an 95th percentiles, and the horizontal line denotes the median. Mean bias and correlation coefficient for each observed and simulated pair included along the top of each panel.

of predicted POA at each of these sites is more consistent with concentrations of HOA + BBOA. This makes sense because predicted POA contains emissions from both anthropogenic and biomass burning sources. However, the simulated POA temporal variations are not well correlated with HOA + BBOA. A correlation coefficient of 0.41 was obtained in the city at the T0 site, but at the edge of the city the correlation was only 0.21 . The correlation of simulated anthropogenic POA and HOA was somewhat higher at both sites. As explained earlier, the poor correlation at the Pico Tres Padres site is likely the result of the $3 \mathrm{~km}$ grid spacing poorly representing the small-scale topography. The correlation between simulated biomass burning POA and BBOA was low 

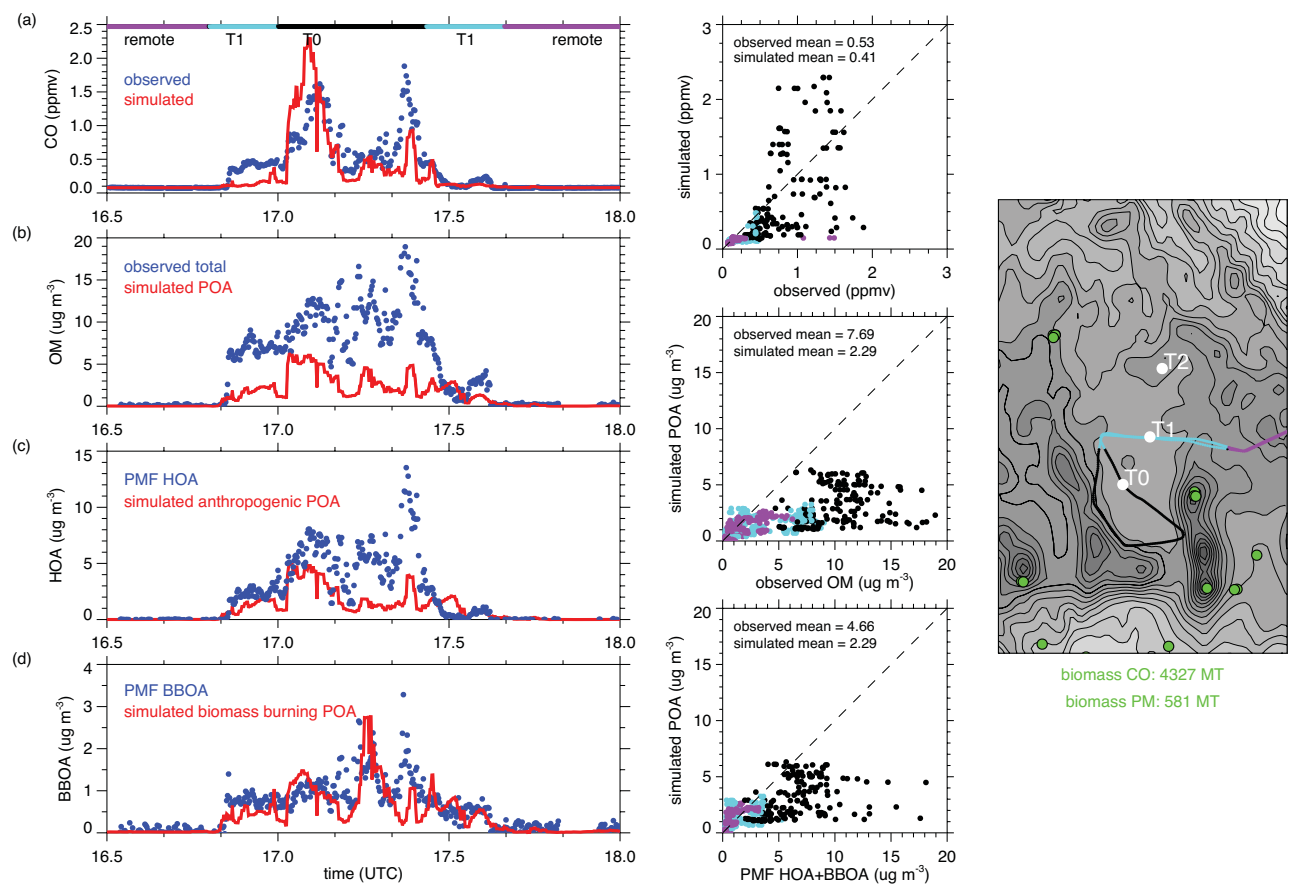

Fig. 15. Observed and simulated (a) CO and (b) total organic mater, (c) anthropogenic organic matter, and (d) biomass burning organic matter along the G-1 flight path during the morning of March 15 on a day with relatively low biomass burning over central Mexico. Right panel depicts biomass-burning sources (green dots) and the G-1 flight path divided into transects over the city and T0 (black), north of the city over the T1 site (light blue), and remote regions between Mexico City and Veracruz (purple).

at all sites because the emissions did not include all types of fires and narrow smoke plumes could easily miss the surface sampling sites even with small transport errors. While there are large errors in the timing of predicted POA, the results indicate that the overall simulated POA mass based on the emission inventories from anthropogenic and biomass burning sources is consistent with primary components of observed organic aerosols. Both the simulated biomass burning POA and BBOA are a larger fraction of the total organic matter mass at the edge of the city at $\mathrm{T} 1$ than downtown at $\mathrm{T} 0$, indicating that biomass burning sources become relatively more important farther away from anthropogenic sources.

AMS instruments were also deployed aboard the G-1 (Kleinman et al., 2008) and C-130 (DeCarlo et al., 2008) aircraft and PMF analysis was performed for a select number of flights. The information on organic components enables predictions of POA to be evaluated further downwind of Mexico City. An example of the observed and predicted $\mathrm{CO}$ and organics for the morning flight of the G-1 on 15 March is shown in Fig. 15. Overall, spatial variations of predicted CO were qualitatively similar to the measurements along aircraft flight path (Fig. 15a). The simulated peak of 2.3 ppm just after 17:00 UTC (11:00 LT) was 0.7 ppm higher than observed as the aircraft passed over the $\mathrm{T} 0$ site. As the aircraft returned over the city the simulated peak of $1.0 \mathrm{ppm}$ was $0.9 \mathrm{ppm}$ lower than observed. The largest scatter in the observed and simulated $\mathrm{CO}$ occurred over the city since timing and loca- tion of the simulated plume was not exactly right. As with the analysis of surface organic aerosols, predicted POA was usually less than the concentration of observed total organic aerosols as seen in the time series and scatter plot in Fig. 15. Mean predicted POA was $2.3 \mu \mathrm{g} \mathrm{m}^{-3}$, while the mean observed total organic matter was $7.7 \mu \mathrm{g} \mathrm{m}^{-3}$. A somewhat better agreement is reached for the scatter plot of predicted POA with $\mathrm{HOA}+\mathrm{BBOA}$ (mean value of $4.7 \mu \mathrm{g} \mathrm{m}^{-3}$ ), but Fig. $15 \mathrm{c}$ and $d$ show that most of the differences result from an underestimation of anthropogenic POA just south and west of the city.

Simulated spatial variations in anthropogenic POA were similar to HOA obtained over the northwestern part of the city as the aircraft passed over T0, although the magnitude of POA was somewhat lower than HOA (Fig. 15c). However, the simulated anthropogenic POA was significantly lower than HOA along the flight legs over the mountains to the south and west of the city. Simulated biomass burning POA and BBOA within the boundary layer along the aircraft flight path over $\mathrm{T} 1$ and the city was usually around $1 \mu \mathrm{g} \mathrm{m}^{-3}$, with no significant peaks to suggest the presence of large fires. Over the city, peak values of biomass burning POA and BBOA were both as high as $2-3 \mu \mathrm{g} \mathrm{m}^{-3}$. The distribution of predicted biomass burning POA (not shown) suggested that multi-day accumulation of smoke contributed to the boundary layer concentrations, rather than the fires surrounding the city on this day. Note that simulated biomass burning POA 

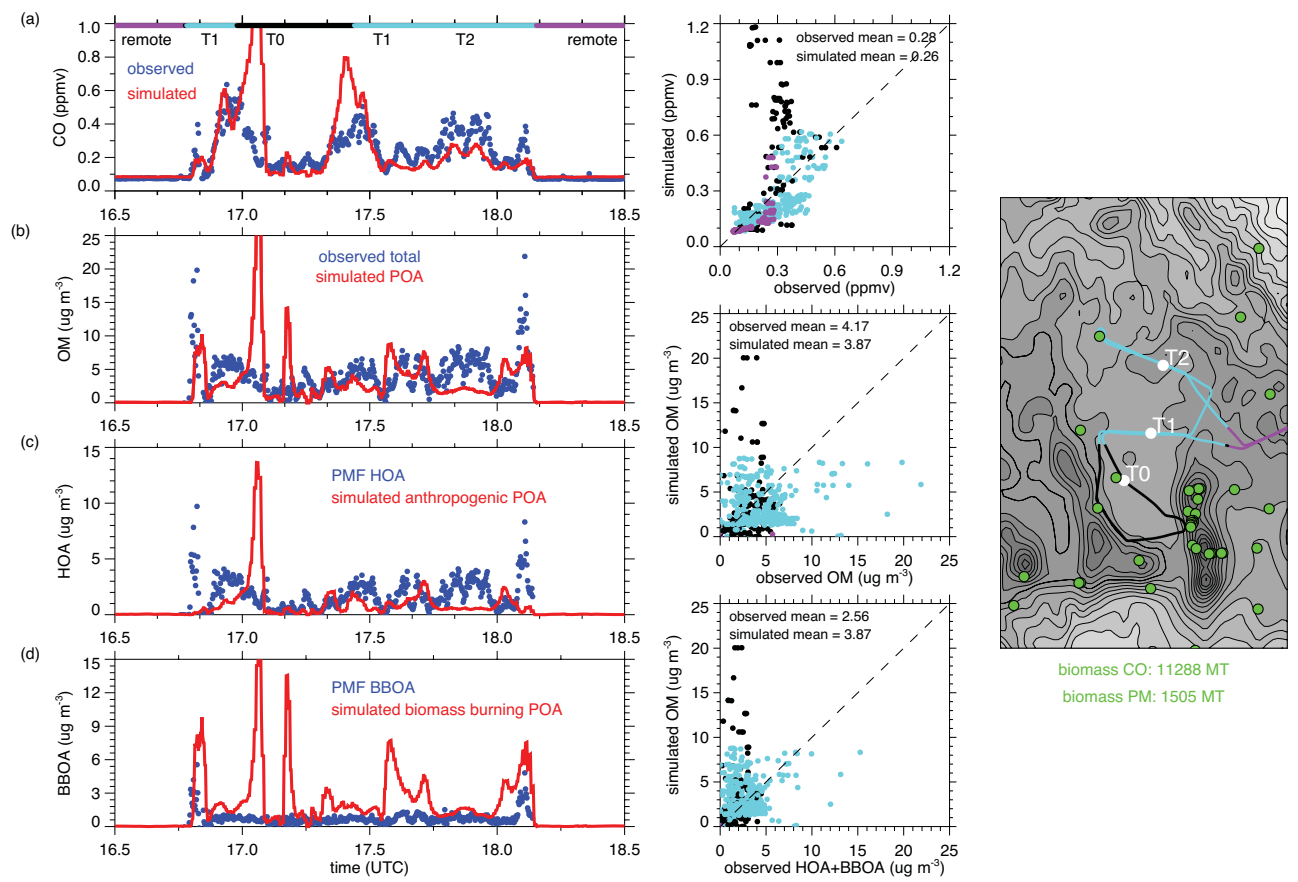

Fig. 16. Same as Fig. 15, except during the morning of 19 March on a day with relatively high biomass burning over central Mexico.

does not include grass fire and other burning sources in the city that may be important.

In contrast to 15 March, 19 March was a day with a many large fires in the vicinity of Mexico City. $\mathrm{CO}$ was predicted reasonably well along the G-1 flight path, as shown in Fig. 16a, and $\mathrm{CO}$ originating from biomass burning was a significant fraction of the total CO (not shown). Unlike 15 March, predicted POA on this day was equal to or higher than the observed total organic matter over many portions of the flight path (Fig. 16b). The average predicted POA over the central plateau was $3.9 \mu \mathrm{g} \mathrm{m}^{-3}$, while the observed total organic matter was $4.2 \mu \mathrm{g} \mathrm{m}^{-3}$ and $\mathrm{HOA}+\mathrm{BBOA}$ was $2.6 \mu \mathrm{g} \mathrm{m}^{-3}$. Figure $16 \mathrm{c}$ indicates that the simulated anthropogenic POA was much higher than HOA in the vicinity of $\mathrm{T} 0$, but was too low in the vicinity of $\mathrm{T} 2$ because the simulated wind were too westerly and transport the Mexico City plume just southeast of T2. Simulated biomass burning POA was almost always higher than BBOA (Fig. 16d), except directly north of the mountain ridge east of the city. For example, predicted biomass burning POA over the fire near T0 was $15 \mu \mathrm{g} \mathrm{m}^{-3}$ even though there was no evidence of smoke from the BBOA time series at that time.

Percentiles are used to summarize the range of observed total organic matter, $\mathrm{HOA}, \mathrm{HOA}+\mathrm{BBOA}$, and simulated POA along all of the available G-1 and C-130 aircraft flight paths, as shown in Fig. 17. In contrast with the percentiles obtained over many days from the surface sites shown in Fig. 14, the range of simulated POA did not consistently agree better with $\mathrm{HOA}+\mathrm{BBOA}$ than with observed total organic matter. On some days simulated POA is similar to
HOA+BBOA, such as the G-1 flights on March 15. On other days predicted POA was lower than the observed total organic aerosols but still higher than the range of $\mathrm{HOA}+\mathrm{BBOA}$ (e.g. 29 March C-130 flight). For the G-1 flights on 18 and 20 March, the simulated POA was frequently less than HOA + BBOA. On 18 March, the predicted OM plume was transported several kilometers north of the aircraft flight path. While the location of the observed and predicted OM plume was similar on 20 March, errors in the simulated boundary layer growth near-surface winds may have diluted the Mexico City plume too fast. When all the flights are considered together, the simulated POA was closest to the $\mathrm{HOA}+\mathrm{BBOA}$ as with the analysis of the surface AMS instrument sites.

Scatter plots that relate primary organic aerosol concentrations and $\mathrm{CO}$ mixing ratios for four geographic regions are shown in Fig. 18 including: (a) at the T0 site and G-1 transects over Mexico City, (b) at the Pico Tres Padres site, (c) at the T1 site and G-1 transects in the vicinity of T1, and G-1 transects in the vicinity of T2 and between Mexico City and Veracruz. At the surface, hourly averages are used and the simulated quantities correspond to the measurement period at each site. Scatter plots for the simulated quantities are qualitatively similar to the observations both at the surface and aloft for all four regions, with some exceptions. Modeled POA rarely exceeded $15 \mu \mathrm{g} \mathrm{m}^{-3}$ in the city (Fig. 18a), although the number of hours observed HOA+BBOA exceeded $15 \mu \mathrm{g} \mathrm{m}^{-3}$ was a small percentage of the measurement period. Most of the observed peak primary organic aerosols were composed primarily of HOA during the morning, indicating that the modeled POA was too low 

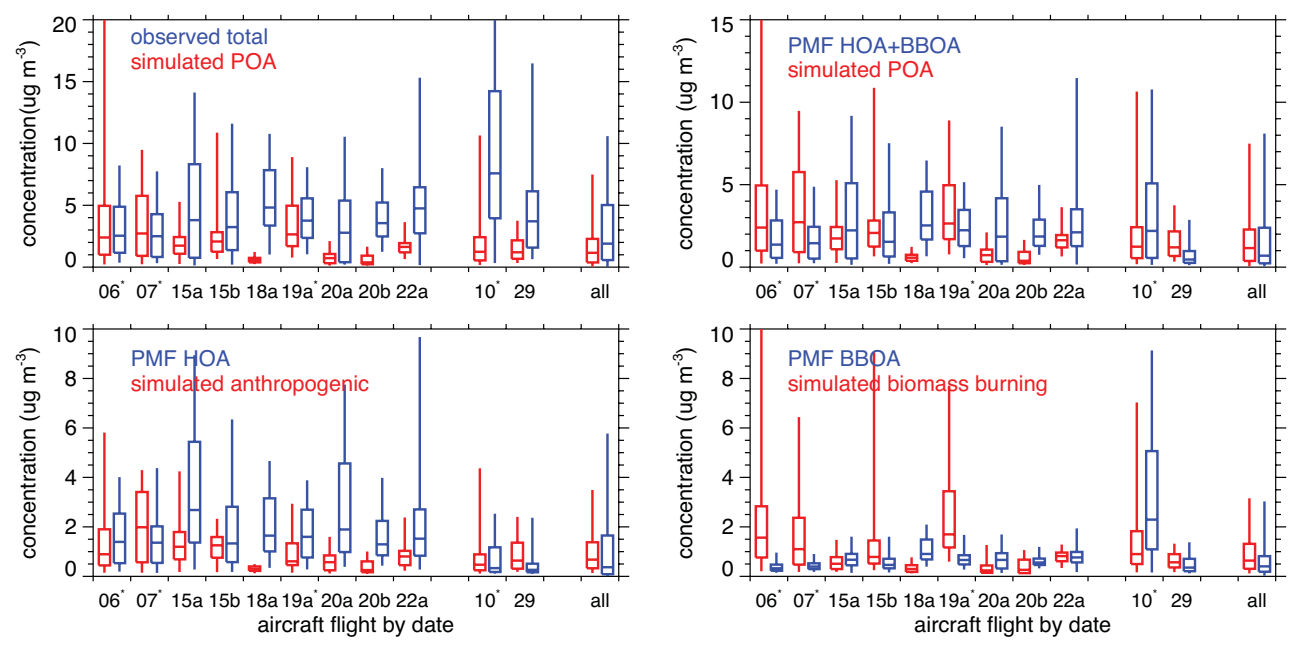

Fig. 17. Comparison of observed organic matter, PMF components, and simulated primary organic matter along the aircraft flight track where horizontal lines denote the median, boxes denote 25 th and 75 th percentiles, and vertical lines denote 5th and 95th percentiles. Data at high altitudes outside of the Mexico City basin have been excluded from the G-1 flight tracks. Asterisk denotes days with five or more large fires within $60 \mathrm{~km}$ of Mexico City.

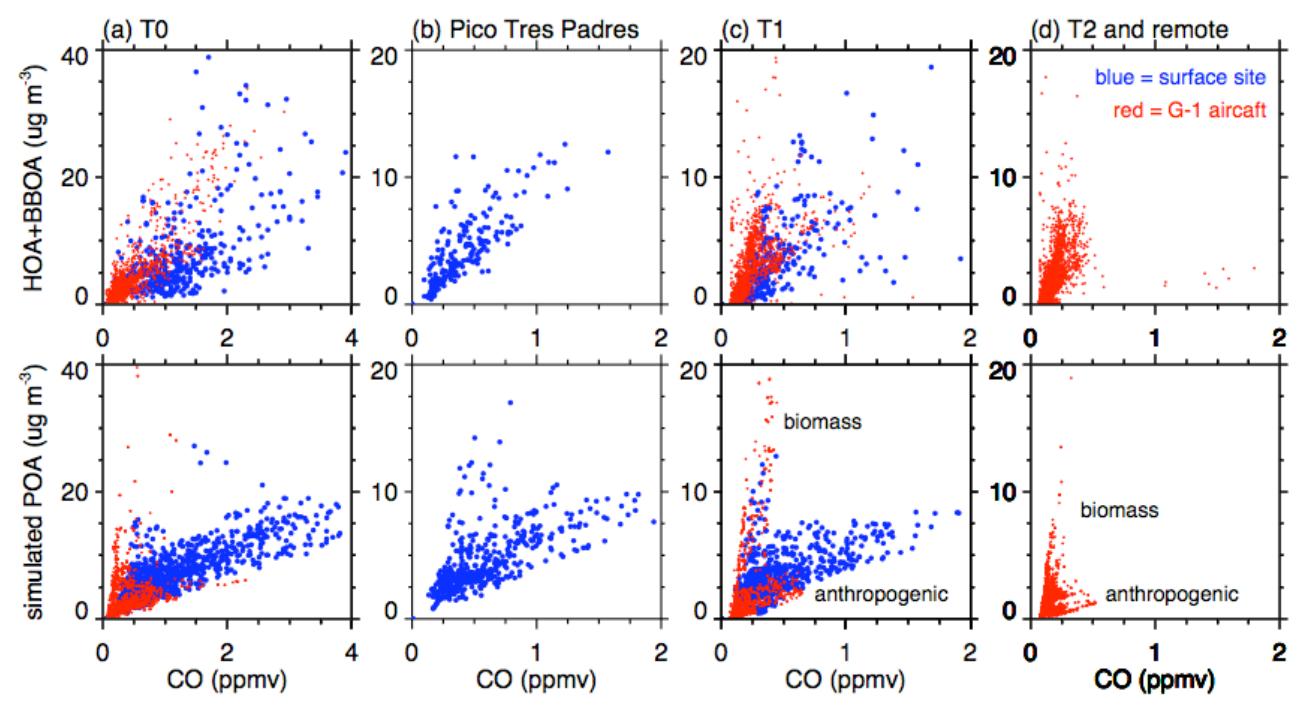

Fig. 18. Primary organic aerosol concentrations versus CO mixing ratios at surface sampling sites and along G-1 flight paths for four geographic regions including: (a) at the T0 site and G-1 transects over Mexico City, (b) at the Pico Tres Padres site, (c) at the T1 site and G-1 transects in the vicinity of T1, and G-1 transects in the vicinity of T2 and between Mexico City and Veracruz. Observed and simulated quantities on the top and bottom panels, respectively.

when traffic emissions are the greatest. At Pico Tres Padres (Fig. 18b) and T1 (Fig. 18c), both the observed and simulated scatter plots had points clustered around two slopes. Those with high primary organic aerosol concentrations and low $\mathrm{CO}$ mixing ratios originated mostly from biomass burning sources, while those with higher $\mathrm{CO}$ mixing ratios originated mostly from anthropogenic sources. The modeled POA/CO for biomass burning exhibited less scatter than the observations, suggesting that there is more variability in the biomass burning POA/CO ratios than indicated in the emission inven- tory (Fig. 2). Further downwind in the vicinity of the T2 site (Fig. 18d), biomass burning sources contributed a larger fraction of both the observed and simulated total primary organic aerosols. As with Fig. 18c, the modeled POA/CO for biomass burning aerosols exhibited less variability and appeared to represent the upper limit of the observations. 


\section{Discussion}

Predictions of POA depend upon the anthropogenic and biomass burning estimates as well as the representation of transport and mixing that affects downwind dispersion of particulates. While the meteorology was simulated reasonably well overall, errors in the simulated circulations will undoubtedly affect the predicted timing and concentration of trace gas and particulate plumes at times. These errors are usually associated with details of the local circulations, rather than the large-scale synoptic circulations as shown in Fig. 5. But based on the evaluation of predicted scalars using data collected at a number of surface sites and from aircraft over a three-week period, we believe that overall magnitude of POA can be assessed using the present model configuration. For the purposes of evaluating emission inventories, it would have been useful to bring the meteorological quantities into even closer agreement with observations, especially near the surface in the vicinity of Mexico City. Data assimilation cannot solve all these issues, however, even for sophisticated variational techniques (e.g. Bei et al., 2008).

In general, $\mathrm{CO}$ was better simulated than EC and POA. All three of these quantities were better simulated in the city at the T0 site than at other locations. This is not surprising since particulate emission estimates are likely to be less understood and more uncertain than emission sources of $\mathrm{CO}$. While the location of $\mathrm{T} 1$ at the edge of the city is useful for understanding chemical evolution over a few hours as pollutants are transported out of the city, the spatial and temporal variations of local emissions will affect local-scale variations in predicted trace gases and particulates in the vicinity $\mathrm{T} 1$. The diurnal variations in $\mathrm{CO}$ and EC was simulated reasonably well at $\mathrm{T} 1$, but the EC concentrations were much lower than observed during the morning between 11:00 and 16:00 UTC (05:00-10:00 LT). Although the overall magnitude of modeled POA and the sum of HOA and BBOA at T1 was similar, the simulated temporal variations of these quantities were not correlated as well as modeled and measured $\mathrm{CO}$ or EC. Two factors contributing the uncertainties in particulate predictions at $\mathrm{T} 1$ could be the characterization of the relative number of gasoline and diesel vehicles along the nearby highway that varies during the day and changes in urban growth at the city edge not accounted for in the emissions inventory.

At remote sites, such as T2 and Paso de Cortes, the simulation results suggest that there would be some improvements in predicted $\mathrm{CO}$ and $\mathrm{EC}$ if the slope of the regional $\mathrm{CO} / \mathrm{EC}$ emission rates were closer to those within the metropolitan area. This also implies that the slope of the regional CO/POA emission rates may need to be closer to those within the metropolitan area. This would lead to lowering of simulated POA outside of the city at the remote sampling sites and along the aircraft transects that are not the Mexico City plume.
At remote sites, biomass burning is also expected to contribute a relatively larger fraction of the observed carbonaceous aerosols. However, biomass burning in this study originates only from large fires and it is not currently possible for models to account for numerous smaller fires that occurred in the region (Yokelson et al., 2007). As with the measurements shown in Fig. 14, numerous small burning sources in the city not accounted by metropolitan emission inventory, may also contribute to observed carbonaceous aerosols. For example, grass fires could be important in this region on some days and have significantly lower PM emission factors (e.g. Sinha et al., 2004) even though most of the aircraft measurements focused on pine forest fires (Yokelson et al., 2007).

The horizontal grid spacing employed in this study also affects the conclusions regarding smoke plumes. The grid spacing artificially spreads a smoke plume at the source over a $9 \mathrm{~km}^{2}$ area; therefore, downwind simulated smoke plumes are likely wider than in reality. While resolution primarily affects the comparisons of model predictions along aircraft flight paths that intersect smoke plumes just downwind of their source (e.g. Fig. 15), uncertainties in the fuel loading for the vegetation types located on the mountains surrounding Mexico City may also contribute to the over-estimations in the emission of particulates for some fires.

Another issue contributing to uncertainties in the POA predictions is volatility. Since emitted organic particulates are semi-volatile (Robinson et al., 2007; Huffman et al., 2008, 2009a, b), then they can evaporate and possibly re-condense further downwind to form SOA. The degree of POA evaporation is unclear. Ambient measurements suggest a volatility somewhat lower than that in the Robinson et al. (2007) model at ambient concentrations (Dzepina et al., 2009), but the volatility under higher concentrations which are most relevant for the evaporation of fresh emissions remains poorly characterized. To the extent that it occurs, evaporation of anthropogenic POA emissions would increase their underestimation, since we assume POA to be non-volatile and predicted POA was similar to HOA + BBOA in the city. On the other hand, the over-prediction of POA downwind of large fires would be improved if a portion of the biomass burning particulates were assumed to be semi-volatile or if lower emission factors were used.

The AMS instrument is now being used widely to obtain information on the composition and size distribution of aerosols (e.g. Zhang et al., 2007). Nevertheless, some caution is warranted when comparing model predictions and AMS measurements. The size cut of the particles that can be measured by the AMS is reported to be $1 \mu \mathrm{m}$ in vacuum aerodynamic diameter $\left(\mathrm{PM}_{1}\right.$ in $\left.d_{v a}\right)$ (e.g. Canagaratna et al., 2007). This size cut corresponds to slightly smaller particles than the $1 \mu \mathrm{m}$ cut in transition-regime aerodynamic diameter $\left(d_{t a}\right)$ that is typically used to define $\mathrm{PM}_{1}$ ambient measurements using cyclone or impactor inlets operated at ambient pressure, with the exact correspondence being dependent on ambient pressure and on particle density and shape and thus 
composition (DeCarlo et al., 2004). For example, for the average density of $1.4 \mathrm{~g} \mathrm{~cm}^{-3}$ calculated from the chemical composition measurements at T0 or CENICA (Aiken et al., 2009; Salcedo et al., 2006) and the pressure of Mexico City, a $\mathrm{PM}_{1}$ cut in $d_{v a}$ corresponds to a $\mathrm{PM}_{0.9}$ cut in $d_{t a}$. There can be some variation in individual aerodynamic lenses as well, which in some cases lead to smaller size cuts (Liu et al., 2007). The $\mathrm{PM}_{1}$ cut in $d_{v a}$ corresponds to $0.7 \mu \mathrm{m}$ physical diameter for spherical particles under the average conditions in Mexico City. Therefore, only predicted organic aerosols from the four size bins below $0.7 \mu \mathrm{m}$ were to compare with the AMS measurements.

The primary source of uncertainty on the measured AMS mass is the collection efficiency (CE). A CE of 0.5 has been determined from many field inter-comparisons for dry nonhighly-acidic particles (e.g. Takegawa et al., 2005; Canagaratna et al., 2007 and references therein) that is expected to apply to the Mexico City conditions, and also with internal AMS light scattering (Cross et al., 2007). This value of CE has been verified with extensive inter-comparisons for Mexico City (Salcedo et al., 2006, 2007; Johnson et al., 2008; DeCarlo et al., 2008; Dunlea et al., 2008; Aiken et al., 2009; Kleinman et al., 2008). However, some uncertainty exists in this value which results in an uncertainty in the measured mass of $\sim 20-25 \%$. Some additional uncertainty on the relative amounts of the PMF components on the order of 5-10\% of the total OM arises from the PMF separation (Ulbrich et al., 2009), which is higher for the unit-resolution data (Aiken et al., 2009). Estimates of the temporal variations and relative contribution of primary anthropogenic, primary biomass burning, and secondary organic aerosols seem qualitatively reasonable, but uncertainties in AMS quantification and PMF output need to be reduced for a more precise evaluation of model predictions of organic aerosols.

Finally, comparing modeled POA in the city using data derived from the AMS instrument at the T0 site to draw conclusions regarding whether estimates of organic aerosol emissions are reasonable must be put into perspective. More firm conclusions over the urban area could be drawn once the AMS data from the 'flux tower' site (Fig. 1c) becomes available and another simulation is performed using a much smaller grid spacing to resolve the terrain of Pico Tres Padres and the gradients in emissions around the Pico Tres Padres and $\mathrm{T} 1$ sites. In contrast, there are $25 \mathrm{CO}$ monitoring sites located across the metropolitan area. While mesoscale models may not simulate temporal variations in $\mathrm{CO}$ at each site perfectly, the spatially averaged observed and simulated values agree reasonably well (Fig. 7) because small errors in transport that move pollutants from one part of the basin to another (Fast and Zhong, 1998) are averaged out.

These issues stress the complexity of modeling organic aerosols and evaluating the predictions of POA using the available measurements. This does not yet consider the additional complexity of understanding SOA processes, such as hydrocarbon precursor photochemistry and gas-to-particle partitioning, and developing schemes that represent those processes in models. Coupling the extensive trace gas hydrocarbon and particulate organic matter measurements to compute the total observed organic carbon (TOOC) in the atmosphere, a concept introduced by Heald et al., (2008), is needed to understand how organic carbon moves between the gas and particle phases. An analysis of TOOC has already been performed using measurements at the $\mathrm{T} 1$ site (de Gouw et al., 2009), and comparisons of simulated TOOC with TOOC derived at all the sites that have both hydrocarbon and organic matter data is needed to evaluate treatments of SOA in the future.

\section{Summary}

This study employs a wide range of measurements made at the surface and aloft to examine the performance of the WRF-Chem chemical transport model in simulating POA in the vicinity of Mexico City during the March 2006 MILAGRO field campaigns. Since the emission inventories and dispersion will affect predictions of total organic matter and consequently total particulate matter, our objective is to assess the uncertainties in predicted POA before testing and evaluating the performance of secondary organic aerosol (SOA) treatments in future studies.

The predicted meteorology was constrained by wind, temperature, and humidity profiles obtained from radar wind profilers and radiosondes by using data assimilation. Independent measurements, such as those from research aircraft, indicate that the model captured the overall local, regional, and synoptic scale circulations. However, errors in the timing and interaction of various thermally driven circulations associated with complex terrain were produced at times near the surface within the Mexico City basin. The growth of the boundary layer depth was predicted reasonably well on most days, except that the afternoon convective boundary layer usually collapsed too quickly around sunset. The model did not include a detailed urban canopy parameterization that would influence local heating and vertical wind shears so that vertical mixing was likely too shallow over the city during some nights.

Before evaluating predicted POA, scalars such as $\mathrm{CO}$ and EC were first used to further assess the role of the predicted thermally-driven circulations, boundary-layer mixing, and their interaction with the larger-scale flows on transport and mixing in the region. $\mathrm{CO}$ was well simulated on most days both over the city and downwind, indicating that transport and mixing processes were usually consistent with the observed meteorological conditions. Predicted and observed diurnal variations of EC in the city were similar, except that simulated EC concentrations during the morning were half of the observed concentrations. Larger errors in EC occurred at remote locations. If the slope of the CO/EC emission rates in the national emission inventory were changed to be 
more consistent with the metropolitan emission inventory, then predictions of both $\mathrm{CO}$ and $\mathrm{EC}$ would likely improve at remote locations.

In contrast with many previous field campaigns, AMS measurements during MILAGRO were available both at ground sites and on research aircraft so that components of organic aerosols derived from PMF at many locations could be used to evaluate the model. Predicted POA was consistently lower than the measured organic matter at the ground sites, which is consistent with the expectation that SOA should be a large fraction of the total organic matter mass. A much better agreement was found when the overall predicted POA was compared with the sum of "primary anthropogenic" (HOA) and "primary biomass burning" (BBOA), suggesting that the overall magnitude of primary organic particulates released was reasonable. The predicted POA was greater than the total observed organic matter for short periods when the aircraft flew directly downwind of large fires, suggesting that biomass burning emission estimates from some large fires may be too high.

Uncertainties in the predictions of organic aerosols will affect estimates of aerosol direct radiative forcing. Global models with their coarse spatial grid spacing cannot resolve strong gradients in particulates, such as those originating from emissions in the vicinity of megacities, so it is problematic to evaluate global model predictions of organic aerosols using point observations. Regional models, however, should be able to resolve most of the spatially and temporally varying processes responsible for the emission, transport, mixing, and removal of POA in the atmosphere. In this study, the magnitude and diurnal variation of POA was predicted reasonably well in the city, but errors increased downwind of Mexico City. While time-averaged observed and predicted magnitude of POA was similar downwind, errors in the predicted diurnal variability produced differences up to a factor of two. These errors in diurnal variability would likely affect the magnitude of aerosol direct radiative forcing during the day as well as influence the amount secondary species condensing on pre-existing particulates. These issues will be examined in subsequent studies that employ WRF-Chem and new treatments of SOA.

Acknowledgements. We thank Wenfang Lei (Massachusetts Institute of Technology) for providing the 2002 MCMA emissions inventory, Marcelo Mena (Universidad Nacional Andrés Bello) for providing the gridded version of the 1999 NEI, and Darrel Baumgardner (Universidad Nacional Autónoma de México) for providing data from the Paso de Cortes site. This research was supported by the US DOE's Atmospheric Sciences Program of the Office of Biological and Environmental Research (OBER) under Contract DE-AC06-76RLO 1830 at Pacific Northwest National Laboratory (PNNL). Computational resources were provided by EMSL, a national scientific user facility located at PNNL and sponsored by the DOE OBER. PNNL is operated for the US DOE by Battelle Memorial Institute. The National Center for Atmospheric Research is sponsored by the National Science
Foundation. Jose Jimenez and his team were supported by DOE ASP (DE-FG02-05ER63981), NSF (ATM-0528634), and EPA STAR (RD-83216101-0).

Edited by: S. Madronich

\section{References}

Ackermann, I. J., Hass, H., Memmesheimer, M., Ebel, A., Binkowski, F. S., and Shankar, U.: Modal aerosol dynamics model for Europe: Development and first applications, Atmos. Environ., 32, 2981-2999, 1998.

Aiken, A. C., Salcedo, D., Cubison, M. J., de Foy, B., Wiedinmyer, Huffman, C. J., DeCarlo, P. F., Ulbrich, I. M., Docherty, K. S., Sueper, D., Kimmel, J. R., Worsnop, D. R., Trimborn, A., Northway, M., Wehrli, M. N., Szidat, S., Prevot, A., Baltensperger, U., Noda, J., Wacker, L., Stone, E. A., Schauer, J. J., Volkamer, R., Fortner, E., Knighton, B., Wang, J., Laskin, A., Zheng, J., Zhang, R., Gaffney, J., Marley, N. A., Querol, X., Paredes-Miranda, G., Arnott, W. P., Molina, L. T., Sosa, G., and Jimenez, J. L.: Mexico City aerosol analysis during MILAGRO using high resolution aerosol mass spectrometry at the urban supersite (T0). Part 1: Fine Particle Composition and Organic Source Apportionment, Atmos. Chem. Phys. Discuss., 9, 8377-8427, 2009.

Aiken, A. C., DeCarlo, P. F., Kroll, J. H., Worsnop, D. R., Huffman, J. A., Docherty, K., Ulbrich, I. M., Mohr, C., Kimmel, J. R., Sueper, D., Zhang, Q., Sun, Y., Trimborn, A., Northway, M., Ziemann, P. J., Canagaratna, M. R., Onasch, T. B., Alfarra, R., Prevot, A. S. H. Dommen, J. Duplissy, J., Metzger, A., Baltensperger, U., and Jimenez, J. L.: O/C and OM/OC ratios of primary, secondary, and ambient organic aerosols with high resolution time-of-flight aerosol mass spectrometry, Environ. Sci. Technol., 42, 4478-4485, doi:10.1021/es703009q, 2008.

Amato, F., Pandolfi, M., Viana, M., Querol, X., Alastuey, A., and Moreno, T.: Spatial and chemical patterns of PM10 in road dust deposited in urban environment, Atmos. Environ. 43, 16501659, 2009.

Baumgarder, D., Grutter, M., Allan, J., Ochoa, C., Rappenglueck, B., Russell, L. M, and Arnott, P: Evolution of anthropogenic pollution at the top of the regional mixed layer over the central Mexico plateau, Atmos. Chem. Phys., 3265-3306, 2009.

Bei, N., de Foy, B., Lei, W., Zavala, M., and Molina, L. T.: Using 3DVAR data assimilation system to improve ozone simulations in the Mexico City basin, Atmos. Chem. Phys, 8, 7353-7366, 2008.

Binkowski, F. S. and Shankar U.: The Regional Particulate Matter Model, 1, Model description and preliminary results, J. Geophys. Res., 100, 26191-26209, 1995.

CAM (Comisión Ambiental Metropolitana): Inventario de Emissiones 2002 de la Zona Metropolitana del Valle de Mexico, Mexico, 2004.

Canagaratna, M. R., Jayne, J. T., Jimenez, J. L., Allan, J. D., Alfarra, M. R., Zhang, Q., Onasch, T. B., Drewnick, F., Coe, H., Middlebrook, A., Delia, A., Williams, L. R., Trimborn, A. M., Northway, M. J., DeCarlo, P. F., Kolb, C. E., Davidovits, P., and Worsnop, D. R.: Chemical and microphysical characterization of ambient aerosols with the Aerodyne Aerosol Mass Spectrometer, Mass. Spec. Rev., 26, 183-222, 2007. 
Christian, T. J., Yokelson, R. J., Cardenas, B., Molina, L. T., Engling, G., and Hsu. S.-C.: Trace gas and particulate emissions from domestic and industrial biofuel use and garbage burning in central Mexico, Atmos. Chem. Phys. Discuss., 9, 10101-10152, 2009.

Chapman, E. G., Gustafson Jr., W. I., Easter, R. C., Barnard, J. C., Ghan, S. J., Pekour, M. S., and Fast, J. D.: Coupling aerosolscloud-radiative processes in the WRF-chem model: Investigating the radiative impact of large point sources, Atmos. Chem. Phys., 9, 945-964, 2009.

Cross, E. S., Slowik, J. G., Davidovits, P., Allan, J. D., Worsnop, D. R., Jayne, J. T., Lewis, D. K., Canagaratna, M., and Onasch, T. B.: Laboratory and ambient particle density determinations using light scattering in conjunction with aerosol mass spectrometry, Aerosol Sci. Technol., 41, 343-359, doi:10.1080/02786820701199736, 2007.

DeCarlo, P., Slowik, J. G., Worsnop, D. R., Davidovits, P., and Jimenez, J. L.: Particle morphology and density characterization by combined mobility and aerodynamic diameter measurements, Part 1: Theory, Aerosol Sci. Technol., 38, 1185-1205, doi:10.1080/027868290903907, 2004.

DeCarlo, P. F., Kimmel, J. R., Trimborn, A., Northway, M. J., Jayne, J. T., Aiken, A. C., Gonin, M., Fuhrer, K., Horvath, T., Docherty, K., Worsnop, D. R., and Jimenez, J. L.: Fielddeployable, high-resolution, time-of-flight aerosol mass spectrometer, Anal. Chem., 78, 8281-8289, 2006.

DeCarlo, P. F., Dunlea, E. J., Kimmel, J. R., Aiken, A. C., Sueper, D., Crounse, J., Wennberg, P. O., Emmons, L., Shinozuka, Y., Clarke, A., Zhou, J., Tomlinson, J., Collins, D. R., Knapp, D., Weinheimer, A. J., Montzka, D. D., Campos, T., and Jimenez, J. L.: Fast airborne aerosol size and chemistry measurements above Mexico City and Central Mexico during the MILAGRO campaign, Atmos. Chem. Phys., 8, 4027-4048, 2008.

de Foy, B., Molina, L. T., and Molina, M. J.: Satellite-derived land surface parameters for mesoscale modeling of the Mexico City basin, Atmos. Chem. Phys., 6, 1315-1330, 2006.

de Foy, B., Lei, W., Zavala, M., Volkamer, R., Samuelsson, J., Mellqvist, J., Galle, B., Martinez, A.-P., Grutter, M., Retama, A., and Molina, L. T.: Modelling constraints on the emission inventory and on vertical dispersion for $\mathrm{CO}$ and $\mathrm{SO}_{2}$ in the Mexico City metropolitan area using solar FTIR and zenith sky UV spectroscopy, Atmos. Chem. Phys., 7, 781-801, 2007.

de Foy, B., Fast, J. D., Paech, S. J., Phillips, D., Walters, J. T., Coulter, R. L., Martin, T. J., Pekour, M. S., Shaw, W. J., Kastendeuch, P. P., Marley, N. A., Retama, A., and Molina, L. T.: Basinscale wind transport during the MILAGRO field campaign and comparison to climatology using cluster analysis, Atmos. Chem. Phys., 8, 1209-1224, 2008,

http://www.atmos-chem-phys.net/8/1209/2008/.

de Gouw, J. A., Middlebrooket, A. M., Warneke, C., al.: Budget of organic carbon in a polluted atmosphere: Results from the New England Air Quality Study in 2002, J. Geophys. Res., 110, D16305, doi:10.1029/2004JD005623, 2005.

de Gouw, J. A., Welsh-Bon, D., Warneke, C., Kuster, W. C., Alexander, A., Baker, A. K., Beyersdorf, A. J., Blake, D. R., Canagaratna, M., Huey, L. G., Onasch, T. B., Schauer, J., Stone, E., Sullivan, A. P., Vargas, O., Weber, R. J., Worsnop, D. R., Xie, Y., and Zaveri, R.: Emission and chemistry of organic carbon in the gas and aerosol phase at a sub-urban site near Mexico City in
March 2006 during the MILAGRO study, Atmos. Chem. Phys., 2009.

Doran, J. C., Barnard, J. C., Arnott, W. P., Cary, R., Coulter, R., Fast, J. D., Kassianov, E. I., Kleinman, L., Laulainen, N. S., Martin, T., Paredes-Miranda, G., Pekour, M. S., Shaw, W.J., Springston, and Yu., X.-Y.: The T1-T2 study: Evolution of aerosol properties downwind of Mexico City, Atmos. Chem. Phys., 7, 1585-1598, 2007, http://www.atmos-chem-phys.net/7/1585/2007/.

Doran, J. C., Fast, J. D., Barnard, J. C., Laskin, A., Desyaterik, Y., Gilles, M. K., and Hopkins, R. J.: Applications of Lagrangian dispersion modeling to the analysis of changes in the specific absorption of elemental carbon, Atmos. Chem. Phys., 8, 13771389, 2008.

Dzepina, K., Arey, J., Marr, L. C., Worsnop, D. R., Salcedo, D., Zhang, Q., Onasch, T. B., Molina, L. T., Molina, M. J., and Jimenez, J. L.: Detection of Particle-Phase Polycyclic Aromatic hydrocarbons in Mexico City using an aerosol mass spectrometer, Int. J. Mass Spec., 263, 152-170, 2007.

Dzepina, K., Volkamer, R. M., Madronich, S., Tulet, P., Ulbrich, I. M., Zhang, Q., Cappa, C. D., Ziemann, P. J., and Jimenez, J. L.: Evaluation of new secondary organic aerosol models for a case study in Mexico City, Atmos. Chem. Phys., 4417-4488, 2009.

Edgerton, S. A., Bian, X., Doran, J. C., et al.: Particulate air pollution in Mexico City: A collaborative research project, J. Air Waste Manag. Assoc., 49(10), 1221-1229, 1999.

Fast, J. D. and Zhong, S.: Meteorological factors associated with inhomogeneous ozone concentrations within the Mexico City basin, J. Geophys. Res., 103, 18927-18946, 1998.

Fast, J. D, Gustafson Jr., W. I., Easter, R. C., Zaveri, R. A., Barnard, J. C., Chapman, E. G., and. Grell, G. A.: Evolution of ozone, particulates, and aerosol direct forcing in an urban area using a new fully-coupled meteorology, chemistry, and aerosol model, J. Geophys. Res., 111, D21305, doi:10.1029/2005JD006721, 2006.

Fast, J. D., de Foy, B., Acevedo Rosas, F., Caetano, E., Carmichael, G., Emmons, L., McKenna, D., Mena, M., Skamarock, W., Tie, X., Coulter, R. L., Barnard, J. C., Wiedinmyer, C., and Madronich S.: A meteorological overview of the MILAGRO field campaigns, Atmos. Chem. Phys., 7, 2233-2257, 2007.

Grell, G. A., Peckham, S. E., Schmitz, R., and McKeen, S. A., Frost, G., Skamarock, W. C., and Eder, B.: Fully coupled "online" chemistry within the WRF model, Atmos. Environ., 39, 69576976, 2005.

Grieshop, A. P., Donahue, N. M., and Robinson, A. L.: Laboratory investigation of photochemical oxidation of organic aerosol from wood fires 2: Analysis of aerosol mass spectrometer data, Atmos. Chem. Phys., 9, 2227-2240, 2009.

Gustafson Jr., W. I., Chapman, E. G., Ghan, S. J., and Fast, J. D.: Impact on modeled cloud characteristics due to simplified treatment of uniform cloud condensation nuclei during NEAQS 2004, Geophys. Res. Lett., 34, L19809, doi:10.1029/2007GL030021, 2007.

Heald, C. L., Goldstein, A. H., Allan, J. D., Aiken, A. C., Apel, E., Atlas, E. L., Baker, A. K., Bates, T. S., Beyersdorf, A. J., Blake, D. R., Campos, T., Coe, H., Crounse, J. D., DeCarlo, P.F., de Gouw, J. A., Dunlea, E. J., Flocke, F. M., Fried, A., Goldan, P., Griffin, R. J., Herndon, S. C., Holloway, J. S., Holzinger, R., Jimenez, J. L., Junkermann, W., Kuster, W. C., Lewis, A. C., Meinardi, S., Millet, D. B., Onasch, T., Polidori, A., Quinn, P. K., 
Riemer, D. D., Roberts, J. M., Salcedo, D., Sive, B., Swanson, A. L., Talbot, R., Warneke, C., Weber, R.J., Weibring, P., Wennberg, P. O., Wittig, A. E., Zhang, R., Zheng, J., and Zheng, W.: Total Observed Organic Carbon (TOOC): A synthesis of North American observations, Atmos. Chem. Phys., 8, 2007-2025, 2008.

Herndon, S. C., Onasch, T. B., Wood, E. C., Kroll, J. H., Canagaratna, M. R., Jayne, J. T., Zavala, M. A., Berk Knighton, W., Mazzoleni, C., Dubey, M. K., Ulbrich, I. M., Jimenez, J. L. Seila, R., de Gouw, J. A., de Foy, B., Fast, J., Molina, L. T., Kolb, C. E., and Worsnop, D. R.: The correlation of secondary organic aerosol with odd oxygen in a megacity outflow, Geophys. Res. Lett., 35, L15804, doi:10.1029/2008GL034058, 2008.

Hodzic, A., Jimenez, J. L., Madronich S., Aiken A. C., Bessagnet, B., Curci, G., Fast, J., Lamarque, J. F., Onasch, T. B., Roux, G., and Ulbrich, I. M., Modeling organic aerosols during MILAGRO: Application of the CHIMERE model and importance of biogenic secondary organic aerosols, Atmos. Chem. Phys. Discuss., 9, 12207-12281, 2009.

Hodzic A., Vautard R., Chazette P., Menut, L., and Bessagnet, B.: Aerosol chemical and optical properties over the Paris area within ESQUIF project, Atmos. Chem. Phys., 6, 3257-3280, 2006.

Huffman, J. A., Ziemann, P. J., Jayne, J. T., Worsnop, D. R., and Jimenez, J. L.: Development and characterization of a fast-stepping/scanning thermodenuder for chemically-resolved aerosol volatility measurements, Aerosol Sci. Technol., 42, 395407, 2008.

Huffman, J. A., Docherty, K. S., Aiken, A. C., Cubison, M. J., Ulbrich, I. M., DeCarlo, P. F., Sueper, D., Jayne, J. T., Worsnop, D. R., Ziemann, P. J. and Jimenez, J. L.: Chemically-resolved aerosol volatility measurements from two megacity field studies, Atmos. Chem. Phys. Discuss., 9, 2645-2697, 2009a.

Huffman, J. A., Docherty, K. S., Mohr, C., Cubison, M. J., Ulbrich, I. M., Ziemann, P. J., Onasch, T. B., and Jimenez, J. L.: Chemically-resolved volatility measurements of organic aerosol from different sources, Environ. Sci. Technol., 43, 5351-5357, doi:10.1021/es803539d, 2009b.

Jacobson, M. Z.: Modeling coagulation among particles of different composition and size, Atmos. Environ., 28, 1327-1338, 1994.

Jazcilevich, A. D., Garcia, A. R., and Ruiz-Suarez, L. G.: A study of air flow patterns affecting pollutant concentrations in the Central Region of Mexico, Atmos. Environ., 37, 183-193, 2003.

Johnson, K. S., Laskin, A., Jimenez, J. L., Shutthanandan, V., Molina, L. T., Salcedo, D., Dzepina, K., and Molina, M. J.: Comparative analysis of urban atmospheric aerosol by ProtonInduced X-ray Emission (PIXE), Proton Elastic Scattering Analysis (PESA), and Aerosol Mass Spectrometry (AMS), Environ. Sci. Technol., 42, 6619-6624, doi:10.1021/es800393e, 2008.

Kleinman, L. I., Springston, S. R., Daum, P. H., Lee, Y.-N., Nunnermacker, L. J., Senum, G. I., Wang, J., Weinstein-Lloyd, J., Alexander, M. L., Hubbe, J., Ortega, J., Canagaratna, M. R., and Jayne, J.: The time evolution of aerosol composition over the Mexico City plateau, Atmos. Chem. Phys., 8, 1559-1575, 2008.

Kondo, Y., Miyazaki, Y., Takegawa, N., Miyakawa, T., Weber, R. J., Jimenez, J. L., Zhang, Q., and Worsnop, D. R.: Oxygenated and water-soluble organic aerosols in Tokyo, J. Geophys. Res., 112, D01203, doi:10.1029/2006JD007056, 2007.

Koo, B., Ansari, A. S., and Pandis, S. N.: Integrated approaches to modeling the organic and inorganic atmospheric aerosol compo- nents, Atmos. Environ., 37, 4757-4768, 2003.

Lanz, V.A., Alfarra, M. R., Baltensperger, U., Buchmann, B., Hüglin, C., and Prévôt, A. S. H.: Source apportionment of submicron organic aerosols at an urban site by factor analytical modelling of aerosol mass spectra, Atmos. Chem. Phys., 7, 15031522, 2007.

Lei, W., de Foy, B., Zavala, M., Volkamer, R., and Molina, L. T.: Characterizing ozone production in the Mexico City metropolitan area: A case study using a chemical transport model, Atmos. Chem. Phys., 7, 1347-1366, 2007.

Liu, Y., Bourgeois, A., Warner, T., Swerdlin, S., and Hacker, J.: Implementation of observation-nudging based on FDDA into WRF for supporting AFEC test operations. 6th WRF Conference, NCAR, Boulder, CO, 10.7, 2006.

Liu, P. S. K., Deng, R., Smith, K. A., Williams, L. R., Jayne, J. T., Canagaratna, M. R., Moore, K., Onasch, T. B., Worsnop, D. R., and Deshler, T.: Transmission efficiency of an aerodynamic focusing lens system: Comparison of model calculations and laboratory measurements for the Aerodyne aerosol mass spectrometer, Aerosol Sci. Technol., 41(8), 721-733, 2007.

Molina, L. T., and Molina, M. J. (Eds.): Air Quality in the Mexico Megacity: An integrated assessment, Kluewer Academic Publishers, 2002.

Molina, L. T., Kolb, C. E., de Foy, B., Lamb, B. K., Brune, W. H., Jimenez, J. L., Ramos-Villegas, R., Sarmiento, J., ParamoFigueroa, V. H., Cardenas, B., Gutierrez-Avedoy, V., and Molina, M. J.: Air Quality in North America's Most Populous City Overview of MCMA-2003 campaign, Atmos. Chem. Phys., 7, 2447-2473, 2007.

Molina, L. T., Madronich, S., Gaffney, J. S., and Singh, H. B.: Overview of MILAGRO/INTEX-B campaign, IGACtivities Newsletter, Issues 38, 2-15, 2008.

Odum, J. R., Hoffman, T., Bowman, F., Collins, D., Flagan, R. C., and Seinfeld, J. H.: Gas/particle partitioning and secondary organic aerosol yields, Environ. Sci. Technol., 30, 2580-2585, 1996.

Pfister, G. G., Emmons, L. K., Hess, P. G., Lamarque, J.-F., Orlando, J. J., Walters, S., Guenther, A., Palmer, P. I., and Lawrence, P. J.: Contribution of isoprene to chemical budgets: A model tracer study with the NCAR CTM MOZART-4, J. Geophys. Res., 113, D05308, doi:10.1029/2007JD008948, 2008.

Querol, X., Pey, J., Minguillon, M. C., Perez, N., Alastuey, A., Viana, M., Moreno, T., Bernabe, R. M., Blanco, S., Cardenas, B., Vega, E., Sosa, G., Escalona, S., Ruiz, H., and Artinano, B: PM speciation an sources in Mexico during the MILAGRO-2006 Campaign, Atmos. Chem. Phys., 8, 111-128, 2008.

Robinson, A. L., Donahue, N. W., Shrivastava, M. K., Weitkamp, E. A., Sage, A. M., Grieshop, A. P., Lane, T. E., Pierce, J. R., and Pandis, S. N.: Rethinking organic aerosols: Semivolatile emissions and photochemical aging, Science, 315, 1259-1262, 2007.

Salcedo, D., Onasch, T. B., Dzepina, K., Canagaratna, M. R., Zhang, Q., Huffman, J. A., DeCarlo, P. F., Jayne, J.T., Mortimer, P., Worsnop, D. R., Kolb, C. E., Johnson, K. S., Zuberi, B., Marr, L.C., Volkamer, R., Molina, L. T., Molina, M. J., Cardenas, B., Bernabé, R. M., Márquez, C., Gaffney, J. S., Marley, N. A., Laskin, A., Shutthanandan, V., Xie, Y., Brune, W., Lesher, R., Shirley, T., and Jimenez, J. L.: Characterization of ambient aerosols in Mexico City during the MCMA-2003 campaign with Aerosol Mass Spectrometry: results from the CENICA Super- 
site, Atmos. Chem. Phys., 6, 925-946, 2006.

Salcedo, D., Onasch, T. B., Canagaratna, M. R., Dzepina, K., Huffman, J. A., Jayne, J. T., Worsnop, D. R., Kolb, C. E., Weimer, S., Drewnick, F., Allan, J. D., Delia, A. E., and Jimenez, J. L.: Technical Note: Use of a beam width probe in an aerosol mass spectrometer to monitor particle collection efficiency in the field, Atmos. Chem. Phys., 7, 549-556, 2007.

Sarrat, C., Lemonsu, A., Masson, V., and Guedalia, D.: Impact of urban heat island on regional atmospheric pollution, Atmos. Environ., 40, 1743-1758, 2006.

Schell, B., Ackermann, I. J., Hass, H., Binkowski, F. S., and Ebel, A.: Modeling the formation of secondary organic aerosol within a comprehensive air quality modeling system, J. Geophys. Res., 106, 28275-28293, 2001.

Shaw, W. J., Pekour, M. S., Coulter, R. L., Martin, T. J., and Walters J. T.: The daytime mixing layer observed by radiosonde, profiler, and lidar during MILAGRO, Atmos. Chem. Phys. Discuss., 7, 15025-15065, 2007.

Shon, Z.-H., Madronich, S., Song, S.-K., Flocke, F. M., Knapp, D. J., Anderson, R. S., Shetter, R. E., Cantrell, C. A., and Hall, S. R.: Characteristics of the NO- $\mathrm{NO}_{2}-\mathrm{O}_{3}$ system in different chemical regimes during the MIRAGE-Mex field campaign, Atmos. Chem. Phys., 8, 7153-7164, 2008.

Simpson, D., Yttri, K. E., Klimont, Z., Kupiainen, K., Caseiro, A., Gelencsér, A., Pio, C., Puxbaum, H., and Legrand, M.: Modeling carbonaceous aerosol over Europe: Analysis of the CARBOSOL and EMEP EC/OC campaigns, J. Geophys. Res., 112, D23S14, doi:10.1029/2006JD008158, 2007.

Sinha, P., Hobbs, P. V., Yokelson, R. J., et al.: Emissions from miombo woodland and dambo grassland savanna fires, J. Geophys. Res., 109, D11305, doi:10.1029/2004JD004521, 2004.

Skamarock, W. C., Klemp, J. B, Dudhia, J., Gill, D. O., Barker, D. M., Duda, M. G., Huang, X.-Y., Wang, W., and Powers, J. G.: A description of the advanced research WRF version 3, NCAR Technical Note, NCAR/TN-475+STR, 113 pp., 2008.

Takegawa, N., Miyazaki, Y., Kondo, Y., Komazaki, Y., Miyakawa, T., Jimenez, J. L., Jayne, J. T., Worsnop, D. R., Allan, J., and Weber, R. J.: Characterization of an Aerodyne Aerosol Mass Spectrometer (AMS): Intercomparison with other aerosol instruments, Aerosol Sci. Technol., 39, 760-770, 2005.

Thorpe, A. and Harrison, R. M.: Sources and properties of nonexhaust particulate matter from road traffic: A review, Sci. Total Environ., 400, 270-282, 2008

Ulbrich, I. M., Canagaratna, M. R., Zhang, Q., Worsnop, D. R., and Jimenez, J. L.: Interpretation of organic components from positive matrix factorization of aerosol mass spectrometric data, Atmos. Chem. Phys., 9, 2891-2918, 2009.
Volkamer, R., Jimenez, J.L., San Martini, F., Dzepina, K., Zhang, Q., Salcedo, D., Molina, L.T., Worsnop, D., and Molina, M.J.: Secondary organic aerosol formation from anthropogenic air pollution: Rapid and higher than expected, Geophys. Res. Lett., 38 L17811, doi:10.1029/2006GL026899, 2006.

Wexler, A. S., Lurmann, F. W., and Seinfeld, J. H.: Modeling urban and regional aerosols - I. Model development, Atmos. Environ., 28, 531-546, 1994.

Wiedinmyer, C., Quayle, B., Geron, C., Beloe, A., McKenzie, D., Zhang, X., O’Neill, S., and Klos Wynne, K.: Estimating emissions from fires in North America for air quality modeling, Atmos. Environ., 40, 3419-3432, 2006.

Wild, O., Zhu, X., and Prather, M. J.: Fast-J: Accurate simulation of in- and below cloud photolysis in tropospheric chemical models, J. Atmos. Chem., 37, 245-282, 2000.

Yokelson, R., Urbanski, S., Atlas, E., Toohey, D., Alvarado, E., Crounse, J., Wennberg, P., Fisher, M., Wold, C., Campos, T., Adachi, K., Buseck, P. R., and Hao, W. M.: Emissions from forest fires near Mexico City, Atmos. Chem. Phys., 7, 6687-6718, 2007.

Zaveri, R. A. and Peters, L. K.: A new lumped structure photochemical mechanism for large-scale applications, J. Geophys. Res., 104, 30387-30415, 1999.

Zaveri, R. A., Easter, R. C., Fast, J. D., and Peters, L. K.: Model for simulating aerosol interactions and chemistry (MOSAIC), J. Geophys. Res., D13204, doi:10.1029/2007JD008792, 2008.

Zhang, Q., Worsnop, D. R., Canagaratna, M. R., and Jimenez, J. L.: Hydrocarbon-like and oxygenated organic aerosols in Pittsburgh: Insights into sources and processes of organic aerosols, Atmos. Chem. Phys., 5, 3289-3311, 2005.

Zhang, Q., Jimenez, J. L., Canagaratna, M. R., Allan, J. D., Coe, H., Ulbrich, I., Alfarra, M. R., Takami, A., Middlebrook, A. M., Sun, Y. L., Dzepina, K., Dunlea, E., Docherty, K., DeCarlo, P. F., Salcedo, D., Onasch, T., Jayne, J. T., Miyoshi, T., Shimono, A., Hatakeyama, S., Takegawa, N., Kondo, Y., Schneider, J., Drewnick, F., Borrmann, S., Weimer, S., Demerjian, K., Williams, P., Bower, K., Bahreini, R., Cottrell, L., Griffin, R. J., Rautiainen, J., Sun, J. Y., Zhang, Y. M., and Worsnop, D. R.: Ubiquity and dominance of oxygenated species in organic aerosols in anthropogenically-influenced Northern Hemisphere midlatitudes, Geophys. Res. Lett., 34, L13801, doi:10.1029/2007GL0299792, 2007. 